\title{
The effect of electrical stimulation therapies on spinal fusion: a cross-disciplinary systematic review and meta-analysis of the preclinical and clinical data
}

\author{
Ethan Cottrill, MS, Zach Pennington, BS, A. Karim Ahmed, BS, Daniel Lubelski, MD, \\ Matthew L. Goodwin, MD, PhD, Alexander Perdomo-Pantoja, MD, Erick M. Westbroek, MD, \\ Nicholas Theodore, MD, Timothy Witham, MD, and Daniel Sciubba, MD
}

Department of Neurosurgery, The Johns Hopkins School of Medicine, Baltimore, Maryland

\begin{abstract}
OBJECTIVE Nonunion is a common complication of spinal fusion surgeries. Electrical stimulation technologies (ESTs)—namely, direct current stimulation (DCS), capacitive coupling stimulation (CCS), and inductive coupling stimulation (ICS)—have been suggested to improve fusion rates. However, the evidence to support their use is based solely on small trials. Here, the authors report the results of meta-analyses of the preclinical and clinical data from the literature to provide estimates of the overall effect of these therapies at large and in subgroups.
\end{abstract}

METHODS A systematic review of the English-language literature was performed using PubMed, Embase, and Web of Science databases. The query of these databases was designed to include all preclinical and clinical studies examining ESTs for spinal fusion. The primary endpoint was the fusion rate at the last follow-up. Meta-analyses were performed using a Freeman-Tukey double arcsine transformation followed by random-effects modeling.

RESULTS A total of 33 articles (17 preclinical, 16 clinical) were identified, of which 11 preclinical studies (257 animals) and 13 clinical studies (2144 patients) were included in the meta-analysis. Among preclinical studies, the mean fusion rates were higher among EST-treated animals (OR 4.79, $p<0.001)$. Clinical studies similarly showed ESTs to increase fusion rates (OR 2.26, p < 0.001). Of EST modalities, only DCS improved fusion rates in both preclinical (OR 5.64, p $<0.001$ ) and clinical (OR 2.13, $p=0.03$ ) populations; ICS improved fusion in clinical studies only (OR 2.45, $p=0.014)$. CCS was not effective at increasing fusion, although only one clinical study was identified. A subanalysis of the clinical studies found that ESTs increased fusion rates in the following populations: patients with difficult-to-fuse spines, those who smoke, and those who underwent multilevel fusions.

CONCLUSIONS The authors found that electrical stimulation devices may produce clinically significant increases in arthrodesis rates among patients undergoing spinal fusion. They also found that the pro-arthrodesis effects seen in preclinical studies are also found in clinical populations, suggesting that findings in animal studies are translatable. Additional research is needed to analyze the cost-effectiveness of these devices.

https://thejns.org/doi/abs/10.3171/2019.5.SPINE19465

KEYWORDS spinal fusion; electrical stimulation; pseudarthrosis; nonunion; surgical technique

$\mathrm{E}$ ACH year, approximately 400,000 Americans undergo a spinal fusion operation for the treatment of neck or back pain, radiculopathy, and/or myelopathy. ${ }^{77}$ These operations account for the highest aggregate hospital cost of any surgical procedure in America, estimated at $\$ 13$ billion in $2011 .{ }^{89}$ Consequently, demonstration of clinical efficacy is paramount given increasing scrutiny of cost-effective care. Prior studies have suggested that clinical improvement following spinal fusion surgery is often in accordance with the radiological success of fusion, as defined by continuous bony union across the fu- sion site. ${ }^{3,59,87}$ For this reason, emphasis has been placed on reducing the rates of nonunion, or pseudarthrosis, which are reported to be as high as $81 \%$ in some small series., ${ }^{9,20}$, 29,32,64,82 Interventions to accomplish this goal include preoperatively addressing risk factors (e.g., diabetes, chronic steroid use, and cigarette use) ${ }^{51}$ and improving operative technique (e.g., adequate decortication, removal of interposing soft tissues, and sufficient bone graft). ${ }^{12}$ Additionally, new technologies are continuously being investigated to enhance the fusion rate, including the use of recombinant human growth factors (e.g., bone morphogenetic pro-

ABBREVIATIONS CCS = capacitive coupling stimulation; DCS = direct current stimulation; ICS = inductive coupling stimulation; PEMF = pulsed electromagnetic field. SUBMITTED April 18, 2019. ACCEPTED May 17, 2019.

INCLUDE WHEN CITING Published online October 8, 2019; DOI: 10.3171/2019.5.SPINE19465. 

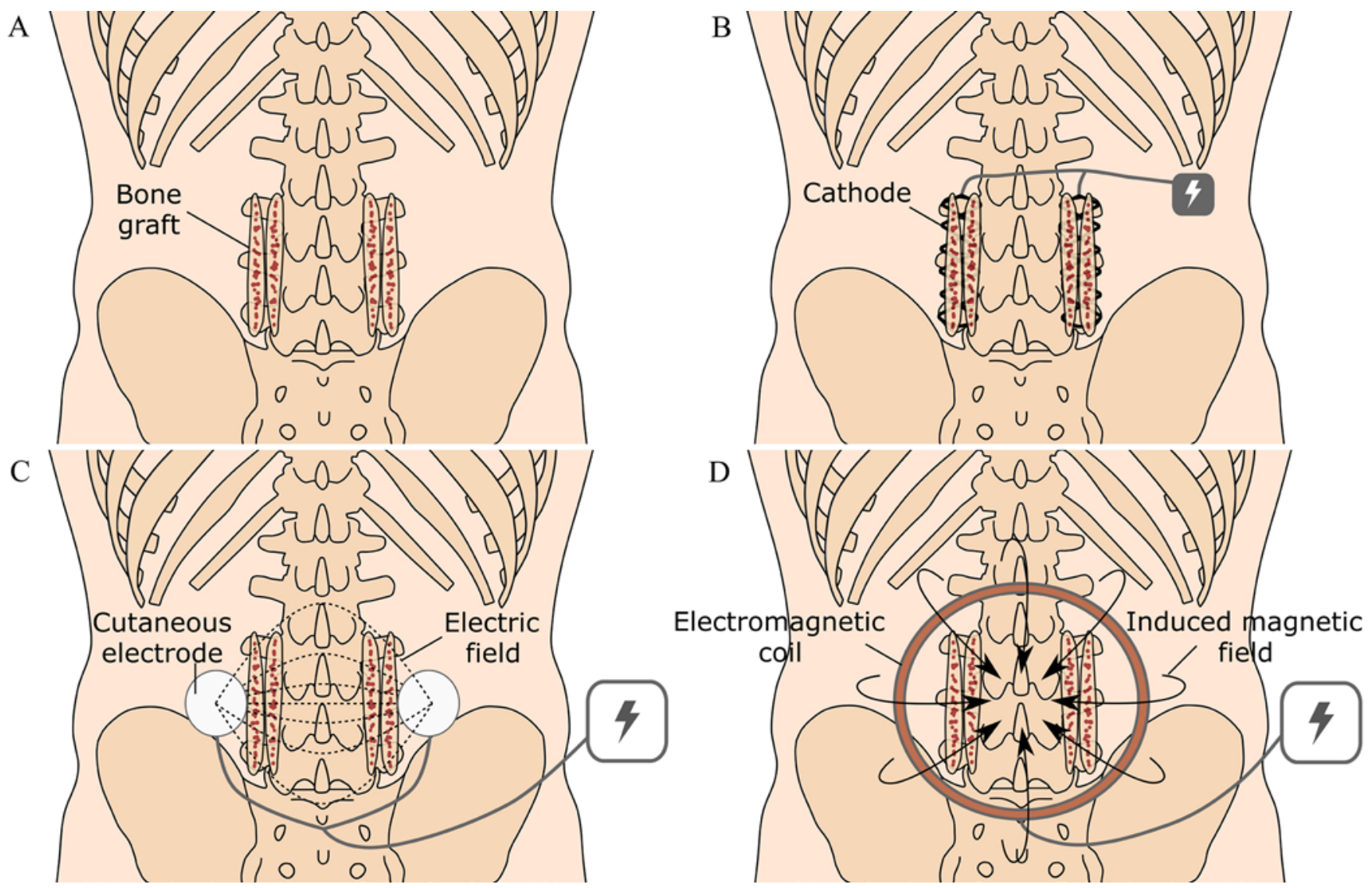

FIG. 1. Conceptual illustrations of the 3 types of electrical stimulation therapies used in spinal fusion. A: Posterolateral L3-5 inter-transverse process spinal fusion using bone graft, without electrical stimulation. B-D: Same procedure illustrating postoperative adjuvant therapy with DCS (B), CCS (C), or ICS (D), sometimes referred to as PEMF. In B, the electric generator is typically implanted subcutaneously. In $C$ and $D$, the electric generators are externally located. Copyright Ethan Cottrill. Published with permission. Figure is available in color online only.

tein-2), ${ }^{27,43,76}$ mesenchymal stem cells, ${ }^{79}$ novel bone graft substitutes, ${ }^{31,73}$ and dynamic instrumentation. ${ }^{65,91}$ Postoperative electrical stimulation therapy has also been suggested as an attractive adjuvant therapy to enhance or accelerate bony union.,49

The use of electrical stimulation therapy to induce fusion has been investigated clinically since at least 1812 , when Birch successfully treated a patient with tibial nonunion using "[s]hocks of electric fluid . . . passed [daily] through the space between the ends of the bones both in direction of the length of the limb and that of its thickness." ${ }^{50}$ A considerable body of evidence has since been generated to support the general concept that electrical energy influences living bone (as well as other biological tissues). ${ }^{6}$ Notably, in the 1950s, Fukada and Yasuda described the piezoelectric effect of bone, defined as the generation of electric potentials in bone subjected to mechanical stresses. Using a custom galvanometer, they documented an electrical potential across the stressed bone, with the compressed bone being electronegative and the side under tension being electropositive. ${ }^{44}$ Subsequently, Friedenberg and Brighton described the bioelectric potentials in bone, in which areas of bone undergoing active repair or growth are electronegative relative to areas at rest. ${ }^{40,41}$ Therapeutic electrical stimulation devices are based on these biophysical principles-namely, that the external application of an electrical stimulus can stimulate bone growth through the induction of a negative bioelectric potential.

There are currently 3 types of electrical stimulation therapies used in spinal fusion: direct current stimulation (DCS), capacitive coupling stimulation (CCS), and inductive coupling stimulation (ICS), also known as pulsed electromagnetic field (PEMF) therapy (Fig. 1). Conventionally, DCS involves the implantation of cathodes (negative electrodes) into the prospective fusion mass and an anode (positive electrode) into the adjoining soft tissue. A continuous electrical current between 5 and $20 \mu \mathrm{A}$ is then delivered to the fusion site via a subcutaneously implanted electric generator; the lifetime of this current is dictated by the charge size of the implanted battery, although most devices operate for a minimum of 6 months. ${ }^{16,39,42}$ CCS, in contrast to DCS, is completely noninvasive and employs two capacitive plates placed on the skin on opposite sides of the fusion site. Alternating current is applied to the plates, setting up an oscillating electric field (1-100 $\mathrm{mV} / \mathrm{cm}$ ). As the battery pack is external, it may be replaced and recharged, allowing for continuous use ( 24 hours/day) 
until there is radiological confirmation of fusion. Lastly, ICS employs electromagnetic coils placed over the fusion site. Alternating current applied to these coils induces an electromagnetic field covering the fusion site. ${ }^{83}$ Compared to CCS, ICS devices require shorter daily usage, with only 30 minutes to 2 hours of continuous use required per day until radiological confirmation of fusion is established. The mechanisms of action and the relative technical advantages and disadvantages of these 3 therapies are summarized in Table 1.1,7,8,10,11,16,17,19,21,23,30,37,66,85,88,92,93

Although prior reviews have described the effects of electrical stimulation therapies on spinal fusion, none to date have systematically evaluated both the preclinical and clinical literature of all 3 available technologies. In this article, we perform such a review as a means of compiling the current evidence and validating the translatability of results achieved using these technologies in animal models. We set out to evaluate the available English-language literature for all 3 technologies, asking of each one: 1) To what degree does the technology improve bony fusion in animal models? 2) To what degree does the technology facilitate bony fusion in humans? Additionally, we report the results of a meta-analysis of the available clinical studies to provide an estimate of the overall effect at large and in subgroups.

\section{Methods}

\section{Electronic Literature Search}

A systematic review of the literature was performed using PubMed, Embase, and Web of Science databases. The search query was designed to obtain all of the available in vivo data (preclinical and clinical) examining the effect of electrical stimulation therapies on spinal fusion. The query for the PubMed database was as follows: (spinal fusion[mesh] OR spine fusion*[tw] OR spinal fusion*[tw] or spinal arthrodes*[tw] OR cervical fusion*[tw] OR lumbar fusion*[tw] OR lumbosacral fusion*[tw] OR interbody fusion*[tw] OR posterolateral fusion*[tw] OR cervical arthrodes*[tw] OR lumbar arthrodes*[tw] OR lumbosacral arthrodes*[tw] OR interbody arthrodes*[tw] OR posterolateral arthrodes*[tw]) AND (electric stimulation[mesh] OR electric stimulation therapy[mesh] OR electromagnetic fields[mesh] OR "electrical stimulation" [tw] OR "pulsed electromagnetic field" " $[\mathrm{tw}]$ OR "electromagnetic pulsing*" $[\mathrm{tw}]$ OR "magnetic fields*" $[\mathrm{tw}]$ OR "direct current stimulation*" $[\mathrm{tw}]$ OR "bone growth stimulation*" $[\mathrm{tw}]$ OR "electrical current*" [tw] OR "capacitively coupl ${ }^{* ”}[\mathrm{tw}]$ OR "capacitive coupl*" [tw] OR "capacitive stimulat*" $[\mathrm{tw}]$ OR "inductively coupl ${ }^{*}$ "[tw] OR "inductive coupl*" ${ }^{*}$ tw] OR "inductive stimulat*"[tw]). This query was stylistically modified for use in the Embase and Web of Science databases. The bibliographies of the included studies were also queried for additional sources.

Included studies were preclinical or clinical peer-reviewed publications with full English-language text availability that evaluated the effects of one or more electrical stimulation therapies on spinal fusion. We defined electrical stimulation as the therapeutic use of electromagnetic energy (including direct current, capacitive coupling, and inductive coupling) with the expressed intent of promot- ing bony fusion after instrumented or noninstrumented spinal fusion. Studies were excluded if they examined a surgical model other than spinal fusion or if they mixed the results of spinal fusion with other surgical models. Eligible studies were screened against these criteria by two reviewers (E.C. and Z.P.); a third reviewer (A.K.A.) served as a referee, resolving any discrepancies between the first two reviewers. Critical Appraisal Checklists obtained from the Joanna Briggs Institute at The University of Adelaide were used to assess the quality of the clinical studies included in the meta-analysis. ${ }^{71}$ Because preclinical studies are all classified as level of evidence V, a similar appraisal was not conducted for them. Additionally, the QUOROM (Quality of Reporting of Meta-analyses) checklist was used for this systematic review and metaanalysis. $^{70}$

\section{Data Extraction}

Studies meeting the inclusion criteria were reviewed to extract details regarding the type of electrical stimulation, specifications of the electrical therapy, means of determining bony fusion, and the overall fusion rate at last follow-up. For preclinical studies, we also recorded details about the animal species and surgical model employed. For clinical studies, we included details on the patient demographics and the surgical approach.

For both preclinical and clinical studies, the primary endpoint was the fusion rate at last follow-up. In preclinical studies, we defined this as the total number of levels fused divided by the total number of levels included in the prospective fusion mass. In clinical studies, we defined the fusion rate as that derived from the proportion of patients experiencing a successful radiological fusion at the last follow-up visit. The definition and method of assessment of fusion were recorded for each study.

\section{Statistical Analysis}

Statistical meta-analyses were performed using $\mathrm{R}$ version 3.4.2 (The R Foundation for Statistical Computing). Separately for the preclinical and clinical studies, we generated mean fusion rates and odds ratios using the Freeman-Tukey double arcsine transformation, a previously established method for normalizing proportions with variance stabilization. ${ }^{38} \mathrm{~A}$ random-effects meta-analysis was then employed to give a pooled estimate of the effect of electrical stimulation on fusion rates. We elected to forego a numbers-needed-to-treat analysis based on these results, as prior reports have demonstrated such estimates to be commonly misleading. ${ }^{81}$ Using this methodology, we also performed subgroup analyses of the clinical data based on smoking status, surgical history (index vs revision procedure), use of interbody devices, region fused, type of bone graft, use of instrumentation, and number of levels fused. For all analyses, an $\alpha$ of 0.05 was used as the definition of statistical significance.

\section{Results}

Our search identified 340 unique articles, and 47 of these met our inclusion criteria (Fig. 2). After reviewing the full texts, we included 17 preclinical studies ${ }^{15,22,25,28,}$ 
Cottrill et al.

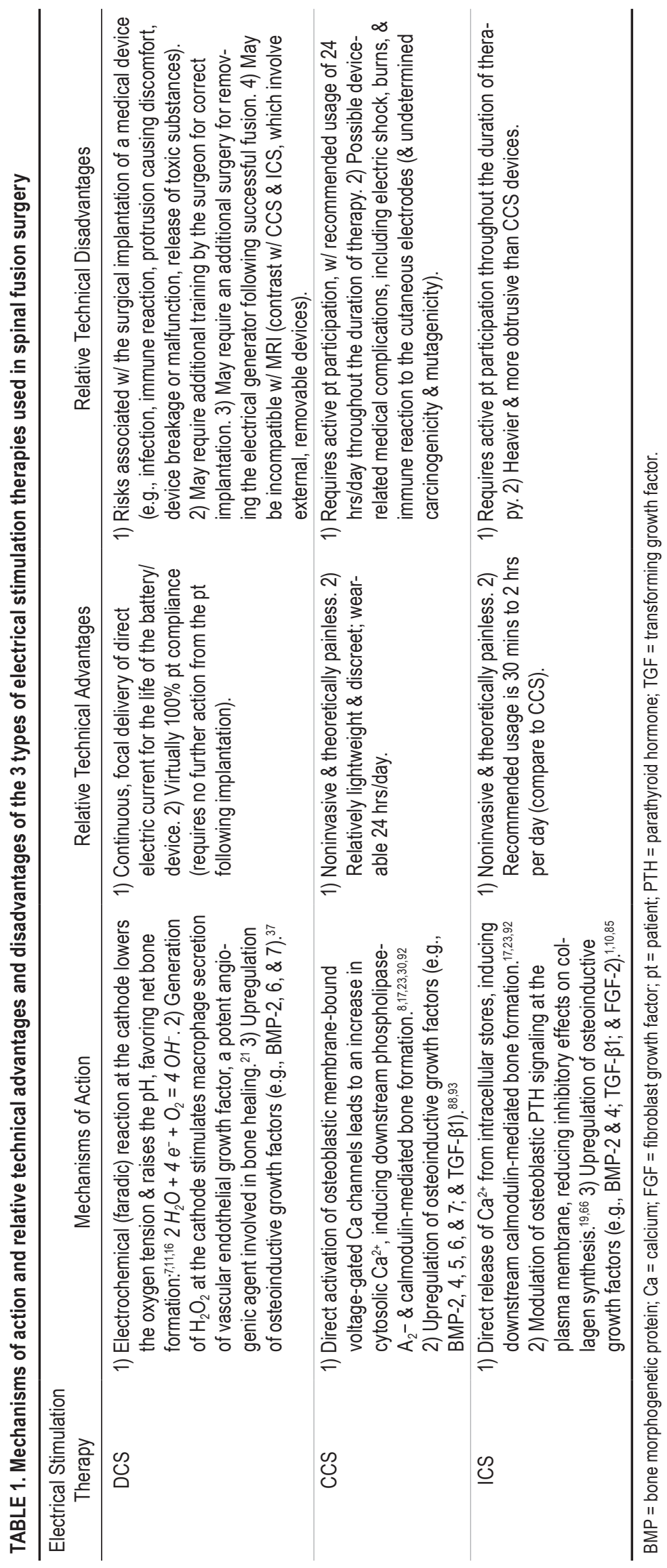




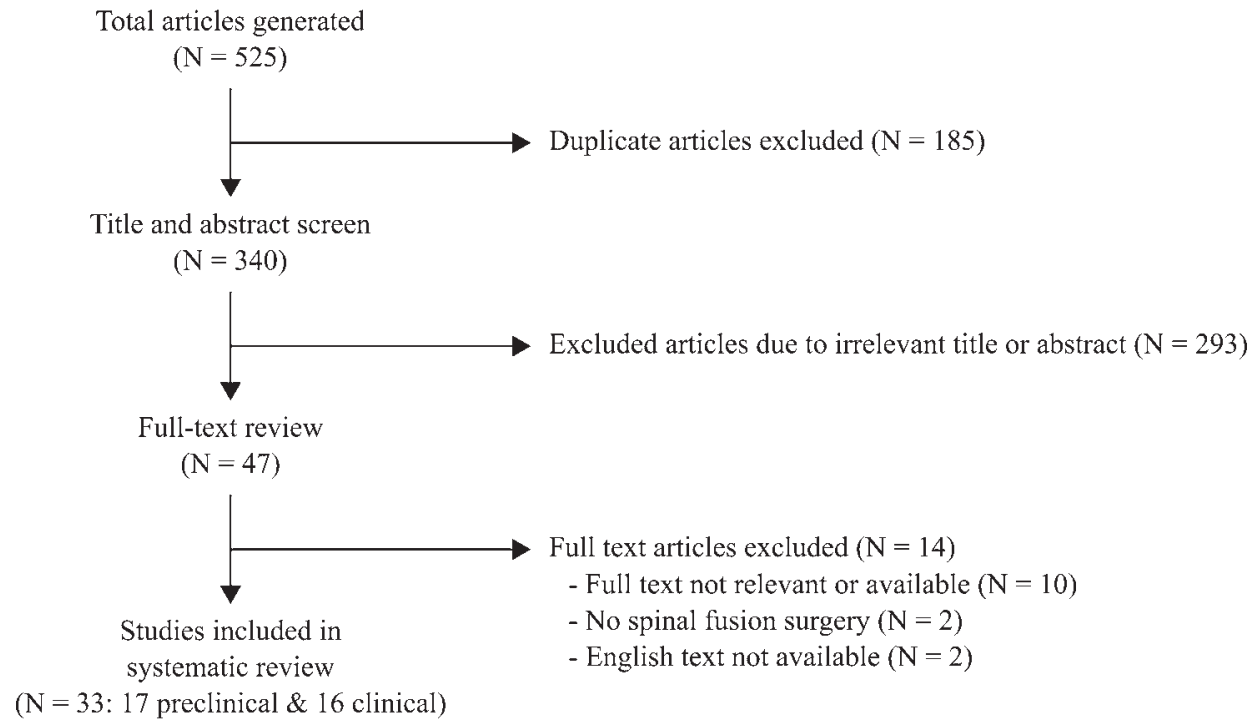

FIG. 2. Diagram of the consolidated standards of reporting trials for article selection.

$35-37,46,48,52,54-56,67,75,86,94$ and 16 clinical studies. ${ }^{5,14,26,34,47,53,57}$, 60,63,68,69,72,74,78,84,90 Among the 14 excluded articles, the reasons for exclusion were lack of full-text availability $(\mathrm{n}=$ $10)$, surgical model other than spinal fusion $(n=2)$, and lack of an English-language translation $(n=2)$. Of these 33 articles, 11 preclinical (257 animals; 273 levels) and 13 clinical (2144 patients) studies were ultimately included in the meta-analysis. The clinical studies were deemed to have sufficient quality to be included in the meta-analysis (Critical Appraisal Checklists). The included articles are summarized in Tables 2 and 3, as well as in Supplemental Tables 1 and 2. Supplemental Fig. 1 plots these studies by year of publication, illustrating the dearth of recent studies.

\section{Overall Effect of Electrical Stimulation Technologies on Spinal Fusion}

In the preclinical literature, the mean fusion rates were higher among animals treated with electrical stimulation therapy $(77.7 \%)$ than among controls (42.0\%). Across all studies, the use of electrical stimulation produced a nearly fivefold increase in the odds of a successful fusion (OR 4.79 [95\% CI 2.51-9.16], p < 0.001) (Table 4). In the clinical literature, electrical stimulation similarly was shown to produce higher rates of fusion versus controls in which no electrical stimulation therapy was administered $(84.9 \%$ vs $73.4 \%$, respectively), although the overall effect was smaller than in the preclinical literature (OR 2.26 [95\% CI 1.48-3.44], $\mathrm{p}<0.001$ ) (Table 4). Figure 3A illustrates the random-effects meta-analysis of the fusion rates from all clinical studies.

\section{Effect of DCS on Spinal Fusion}

Eleven preclinical and 9 clinical studies investigating the effect of DCS on spinal fusion were identified, and 8 preclinical and 6 clinical studies were included in the meta-analysis.

\section{Preclinical Data}

The preclinical studies (Table 2) involved rat $(\mathrm{n}=1)$, rabbit $(n=4), \operatorname{dog}(n=2)$, pig $(n=1)$, sheep $(n=1)$, goat $(n$ $=1$ ), and monkey $(n=1)$ spinal fusion models. All surgical models involved one-level fusions of the lumbar spine, with 3 using posterior facet joint fusion, 5 using posterolateral inter-transverse process fusion, and 3 using interbody fusion. Among these studies, 11 used autograft, 1 used allograft, and 1 used synthetic bone graft; 3 of the studies employed instrumentation in the fusion construct. All but one study used implantable electrodes in the fusion beds. The remaining study routed electrical current through pedicle screws and rods. ${ }^{67}$

The reported fusion rates ranged between $70 \%$ and $100 \%$ for the treatment group and between $0 \%$ and $73 \%$ for controls (Supplemental Fig. 2A). On meta-analysis, the mean fusion rate was found to be significantly higher in DCS-treated levels than in controls (OR 5.64 [95\% CI 2.64-12.06], p < 0.001) (Table 4).

\section{Clinical Data}

Nine clinical studies examined the effects of DCS on spinal fusion: 8 studies in adult cohorts and 1 study in a pediatric cohort (Table 3). Four studies examined its use in patients with difficult-to-fuse spines using the following definitions: 1 ) age $>60$ years $;{ }^{5}$ 2) multiple prior spine surgeries, failed prior fusion, segmental instability, spinal stenosis, and/or spondylolisthesis; ${ }^{60} 3$ ) multilevel fusion, failed prior fusion, and/or grade II or worse spondylolisthesis; ${ }^{84}$ and 4) age $>65$ years, presence of rheumatoid arthritis, failed prior fusion, infection, and/or immunosuppression..$^{90}$ One study was restricted to index procedures, while 8 included both index or revision procedures. Only 1 study employed interbody fusion; the remaining 8 used solely posterior/posterolateral fusion. The spinal segments investigated were cervical in 1 study and lumbar/lumbosacral in 8 . Six studies used autograft only, and 


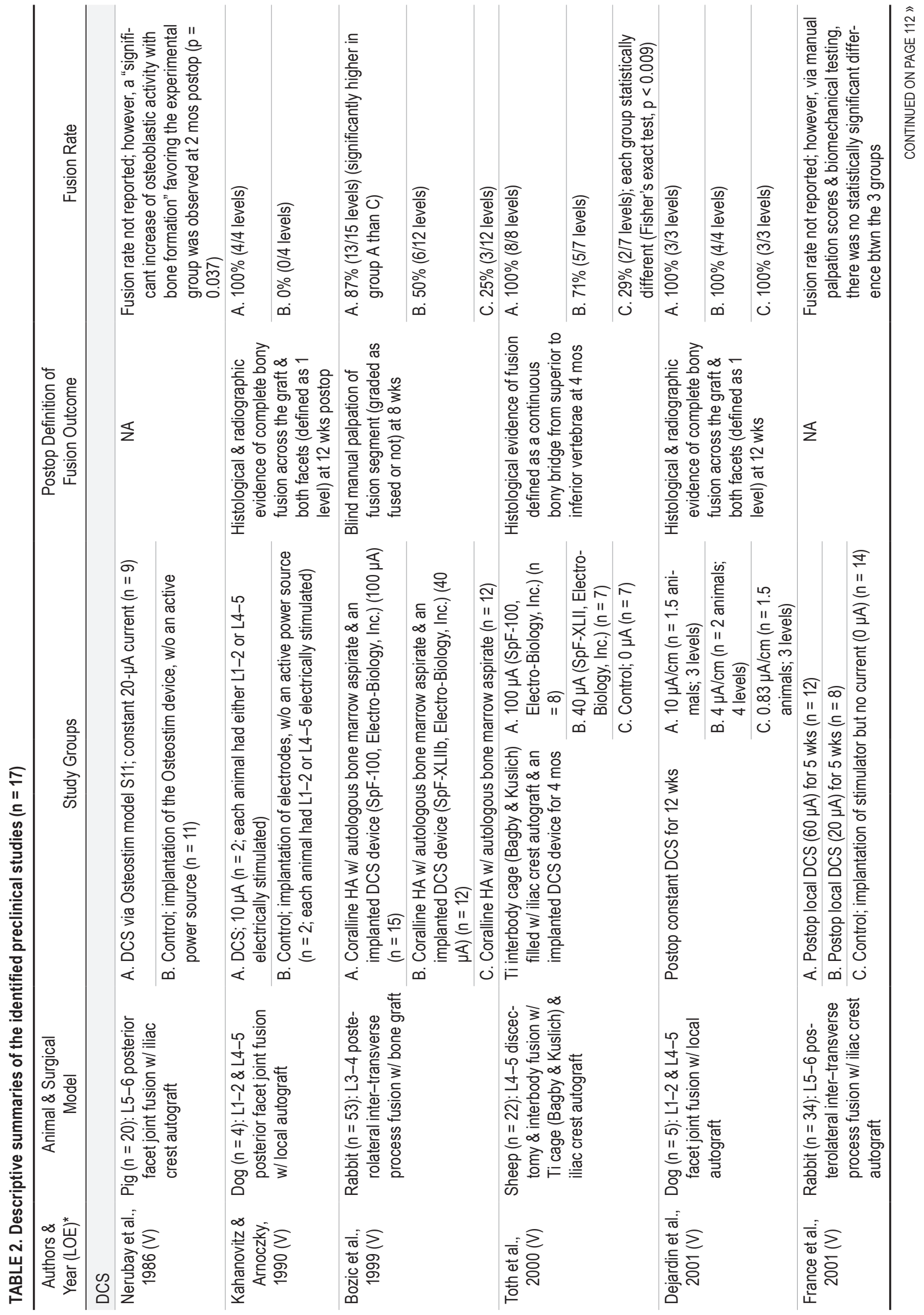




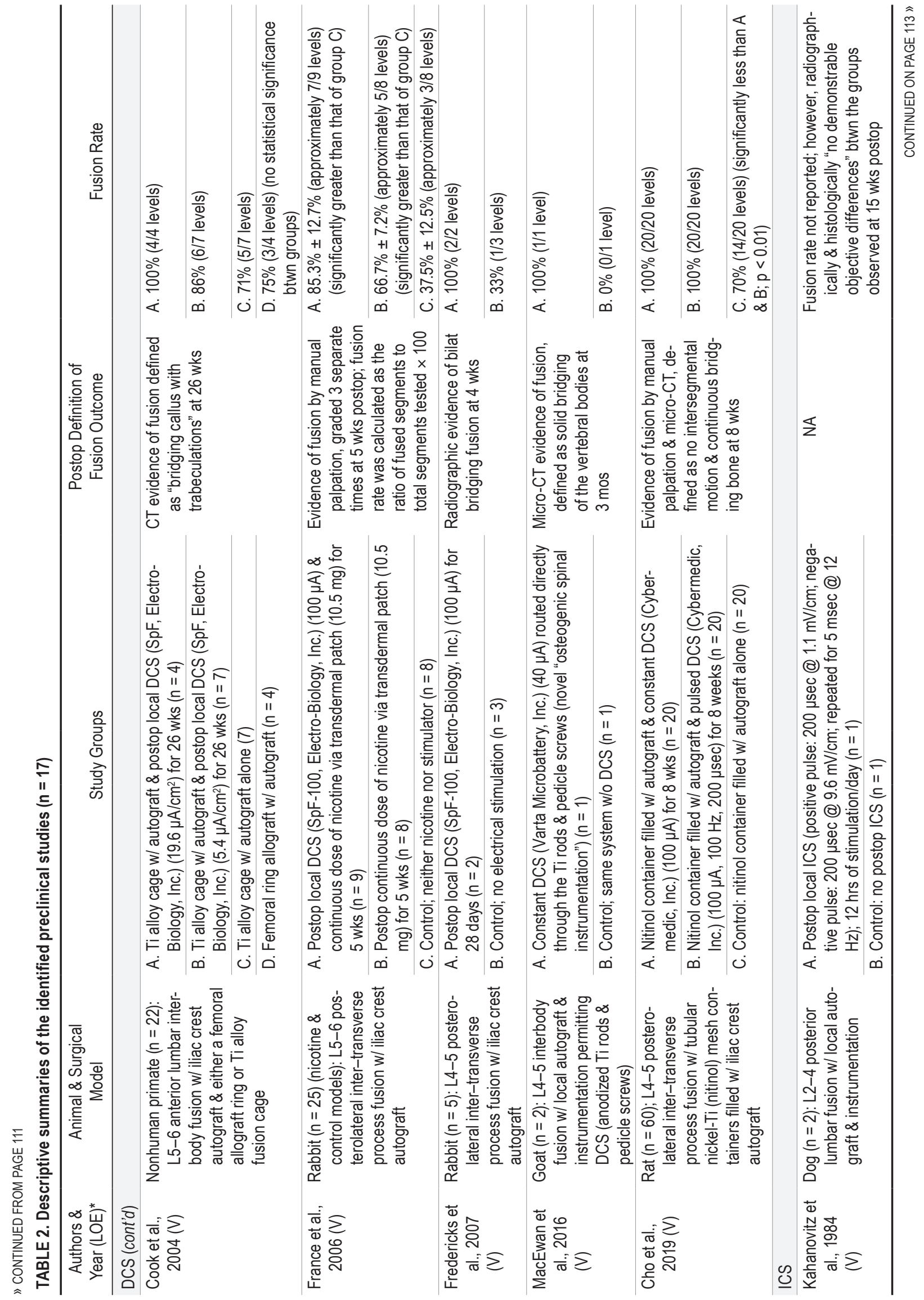




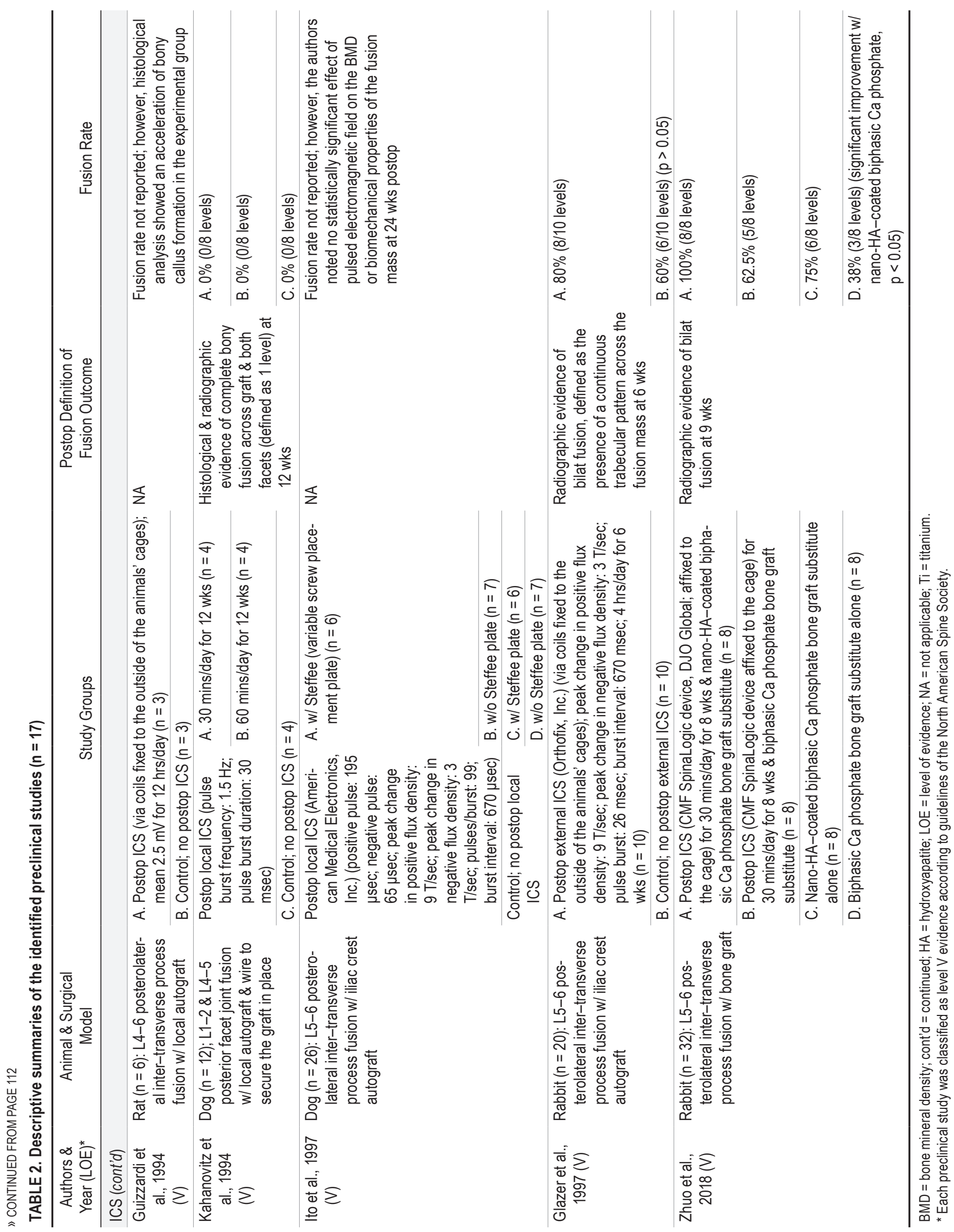




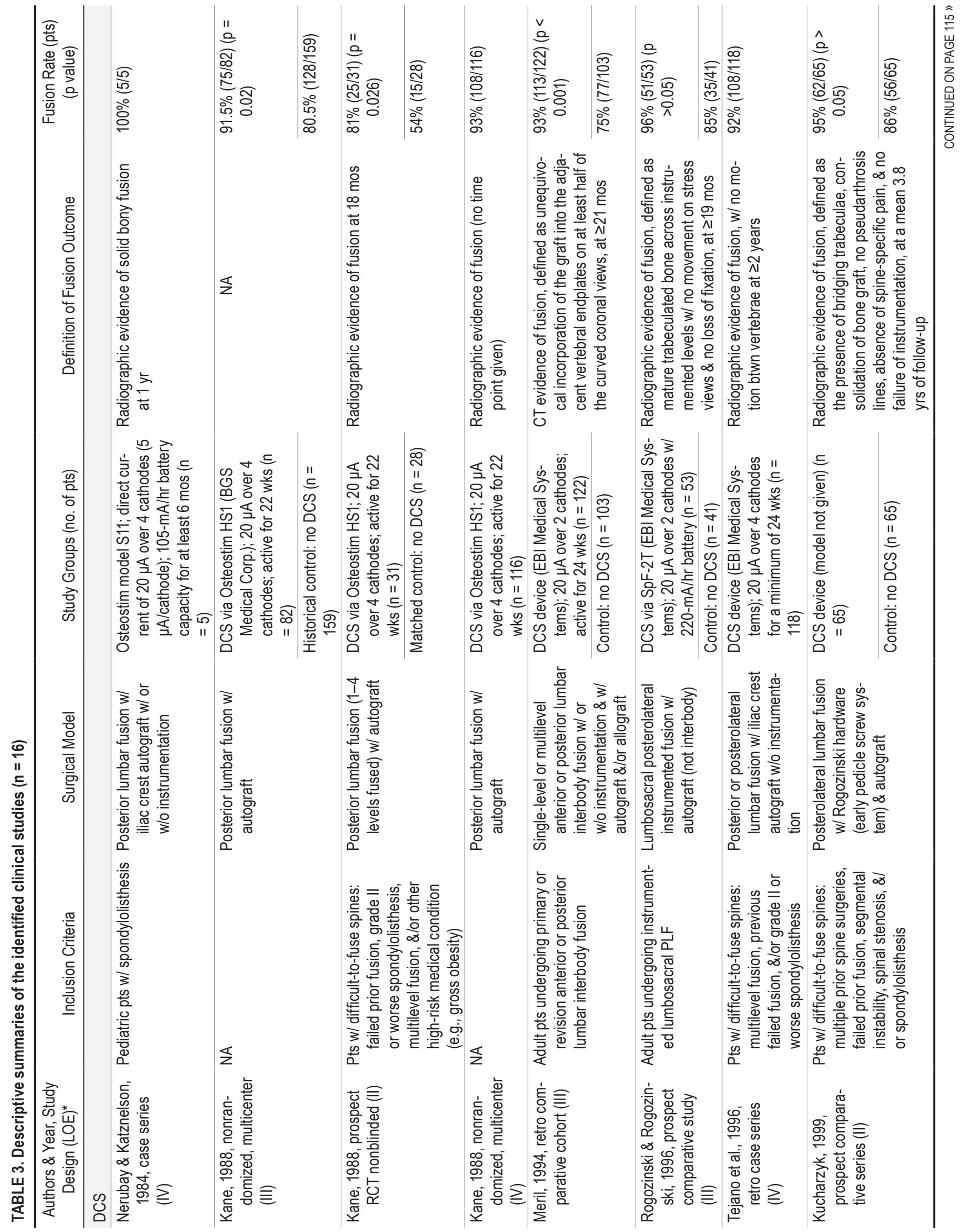




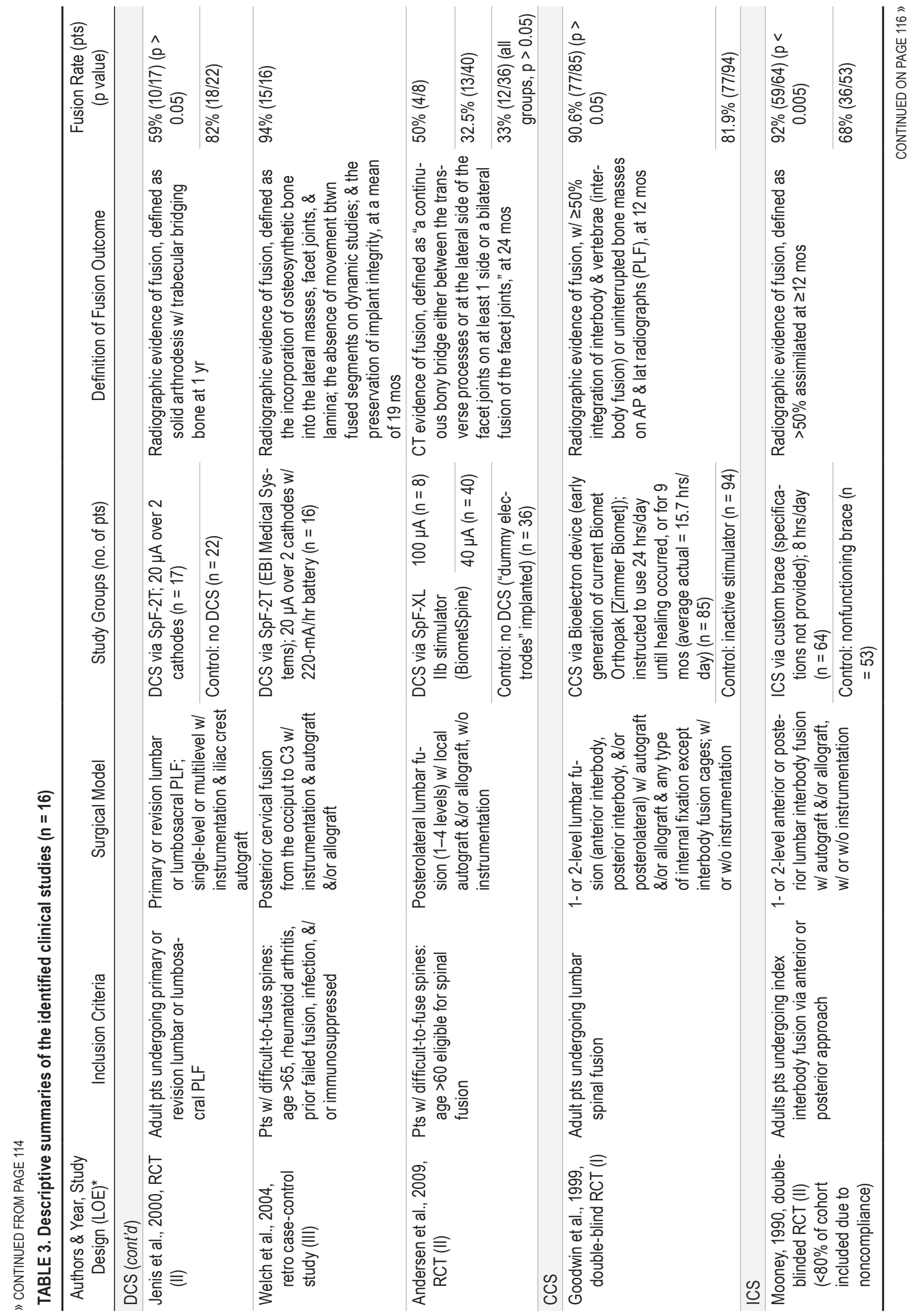




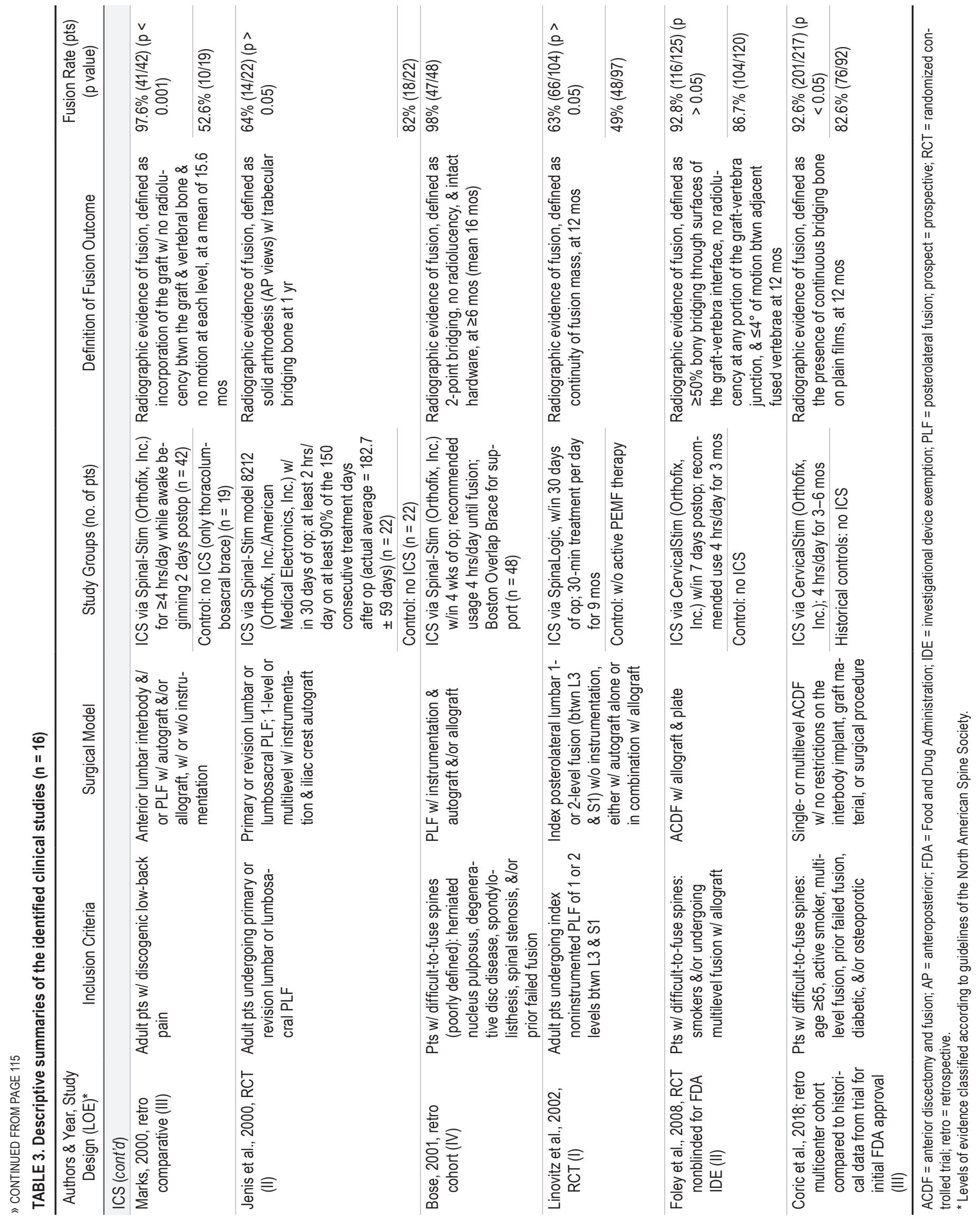


TABLE 4. Mean fusion rates and odds ratios for the preclinical and clinical studies determined by random-effects meta-analysis*

\begin{tabular}{|c|c|c|c|c|c|}
\hline \multirow{2}{*}{$\begin{array}{c}\text { Type of } \\
\text { EST }\end{array}$} & \multirow[b]{2}{*}{ Type of Study \& Authors \& Year } & \multicolumn{2}{|c|}{ Fusion Rate (no. fused/total) $\dagger$} & \multirow[b]{2}{*}{ Cochran's Q } & \multirow[b]{2}{*}{ OR $(95 \% \mathrm{Cl}) \& \mathrm{p}$ Value } \\
\hline & & Stimulation Group & Control Group & & \\
\hline \multirow{18}{*}{ DCS } & Preclinical & & & & \\
\hline & Kahanovitz \& Arnoczky, 1990 & $4 / 4$ & $0 / 4$ & 5.45 & $5.64(2.64-12.06) ; p<0.001$ \\
\hline & Bozic, 1999 & $19 / 27$ & $11 / 26$ & & \\
\hline & Toth et al., 2000 & $13 / 15$ & $2 / 7$ & & \\
\hline & Cook et al., 2004 & $10 / 11$ & $8 / 11$ & & \\
\hline & France et al., 2006 & $7 / 9$ & $8 / 16$ & & \\
\hline & Fredericks et al., 2007 & $2 / 2$ & $1 / 3$ & & \\
\hline & MacEwan et al., 2016 & $1 / 1$ & $0 / 1$ & & \\
\hline & Cho et al., 2019 & $40 / 40$ & $14 / 20$ & & \\
\hline & Overall $(95 \% \mathrm{Cl})$ & $87.6 \%(74.2-96.5 \%)$ & $45.3 \%(30.0-61.1 \%)$ & & \\
\hline & Clinical & & & & \\
\hline & Kane, 1998 & $208 / 229$ & $143 / 187$ & 13.60 & $2.13(1.08-4.21) ; p=0.03$ \\
\hline & Meril, 1994 & $113 / 122$ & $77 / 103$ & & \\
\hline & Rogozinski \& Rogozinski, 1996 & $51 / 53$ & $35 / 41$ & & \\
\hline & Kucharzyk, 1999 & $62 / 65$ & $56 / 65$ & & \\
\hline & Jenis et al., 2000 & $10 / 17$ & $18 / 22$ & & \\
\hline & Andersen et al., 2009 & $17 / 48$ & $12 / 36$ & & \\
\hline & Overall $(95 \% \mathrm{Cl})$ & $82.2 \%(65.8-94.1 \%)$ & $73.9 \%(61.7-84.4 \%)$ & & \\
\hline \multirow{3}{*}{ CCS } & Clinical & & & 0 & $2.12(0.87-5.21) ; p>0.05$ \\
\hline & Goodwin et al., 1999 & $77 / 85$ & $77 / 94$ & & \\
\hline & Overall $(95 \% \mathrm{Cl})$ & $90.6 \%(88.3-95.8 \%)$ & $81.9 \%(72.6-89.1 \%)$ & & \\
\hline \multirow{13}{*}{ ICS } & Preclinical & & & & \\
\hline & Kahanovitz et al., 1994 & $0 / 16$ & $0 / 8$ & 0.03 & $3.08(0.88-10.72) ; p>0.05$ \\
\hline & Glazer et al., 1997 & $8 / 10$ & $6 / 10$ & & \\
\hline & Zhuo et al., 2018 & $13 / 16$ & $9 / 16$ & & \\
\hline & Overall $(95 \% \mathrm{Cl})$ & $47.8 \%(1.1-97.8 \%)$ & $35.7 \%(4.9-75.9 \%)$ & & \\
\hline & Clinical & & & & \\
\hline & Mooney, 1990 & $59 / 64$ & $36 / 53$ & 16.17 & $2.45(1.20-4.99) ; p=0.014$ \\
\hline & Marks, 2000 & $41 / 42$ & $10 / 19$ & & \\
\hline & Jenis et al., 2000 & $14 / 22$ & $18 / 22$ & & \\
\hline & Linovitz, 2002 & $66 / 104$ & $48 / 97$ & & \\
\hline & Foley et al., 2008 & $116 / 125$ & $104 / 120$ & & \\
\hline & Coric et al., 2018 & $201 / 217$ & $76 / 92$ & & \\
\hline & Overall $(95 \% \mathrm{Cl})$ & $86.0 \%(74.2-94.6 \%)$ & $71.2 \%(56.2-84.1 \%)$ & & \\
\hline \multirow{4}{*}{ All } & Preclinical & & & & \\
\hline & Overall $(95 \% \mathrm{Cl})$ & $77.7 \%(54.2-94.3 \%)$ & $42.0 \%(27.5-57.2 \%)$ & 6.15 & $4.79(2.51-9.16) ; p<0.001$ \\
\hline & Clinical & & & & \\
\hline & Overall $(95 \% \mathrm{Cl})$ & $84.9 \%(76.8-91.4 \%)$ & $73.4 \%(65.4-80.8 \%)$ & 29.92 & $2.26(1.48-3.44) ; p<0.001$ \\
\hline
\end{tabular}

Boldface type indicates statistical significance.

* Only studies reporting the fusion rates for both the intervention (i.e., electrical stimulation) and control groups were included in the meta-analysis.

$\dagger$ For preclinical studies, the fusion rate was defined as the number of bilateral vertebral levels fused divided by the total number of levels attempted. For clinical studies, the fusion rate was defined as the number of patients experiencing successful fusion divided by the total number of patients undergoing surgery. For the analysis of preclinical data, where the fusion rate was 0 in some cases, delta was set to 0.5 (Haldane-Anscombe correction). For clinical studies, where the fusion rate was always greater than 0 , delta was set to zero.

the remaining 3 used autograft and/or allograft. Instrumentation was placed in all patients in 4 studies and in some patients in 2 studies; 3 studies used in situ fusion only (Table 3$)$.

The fusion rate ranged from $35 \%$ to $96 \%$ for treated patients and from $33 \%$ to $86 \%$ in controls (Supplemental Fig. 3A). In the meta-analysis, patients treated with DCS were found to have a significantly higher fusion rate at the last follow-up than the control patients (OR 2.13 [95\% CI 1.08-4.21], $\mathrm{p}=0.03$ ) (Table 4 and Fig. 3B). 


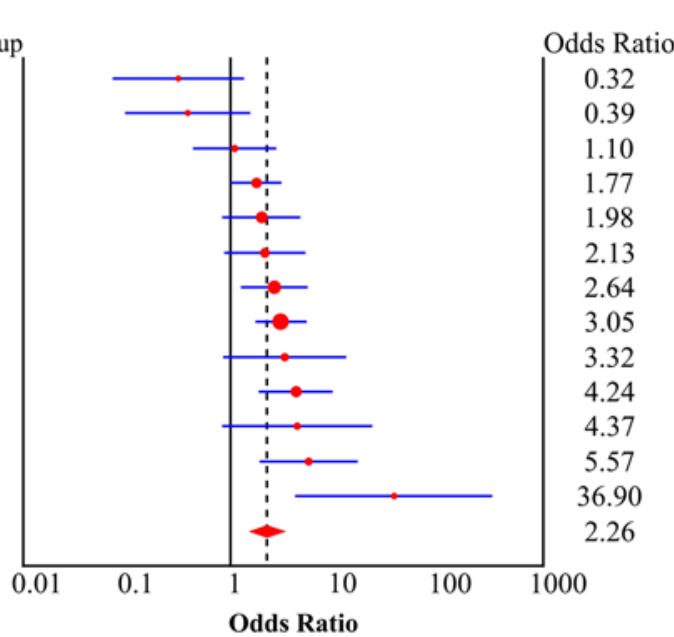

95\% CI Weight \% 0.07-1.36 $\quad 5.31$

Fusion Rate (No. Fused/Total)

Stimulation Group Control Group

$\begin{array}{rcc}\text { Jenis et al., 2000 (DCS) } & 10 / 17 & 18 / 22 \\ \text { Andersen et al., 2009 } & 17 / 48 & 12 / 36 \\ \text { Kane, 1988 } & 208 / 229 & 143 / 187 \\ \text { Kucharzyk, 1999 } & 62 / 65 & 56 / 65 \\ \text { Meril, 1994 } & 113 / 122 & 77 / 103 \\ \text { Rogozinski \& Rogozinski, 1996 } & 51 / 53 & 35 / 41 \\ & & \text { Average (Random Effects) } \\ & & \text { Cochran's Q }=13.6 \mid \mathrm{I}^{2}=63.2 \%\end{array}$

C

Fusion Rate (No. Fused/Total)

Stimulation Group Control Group
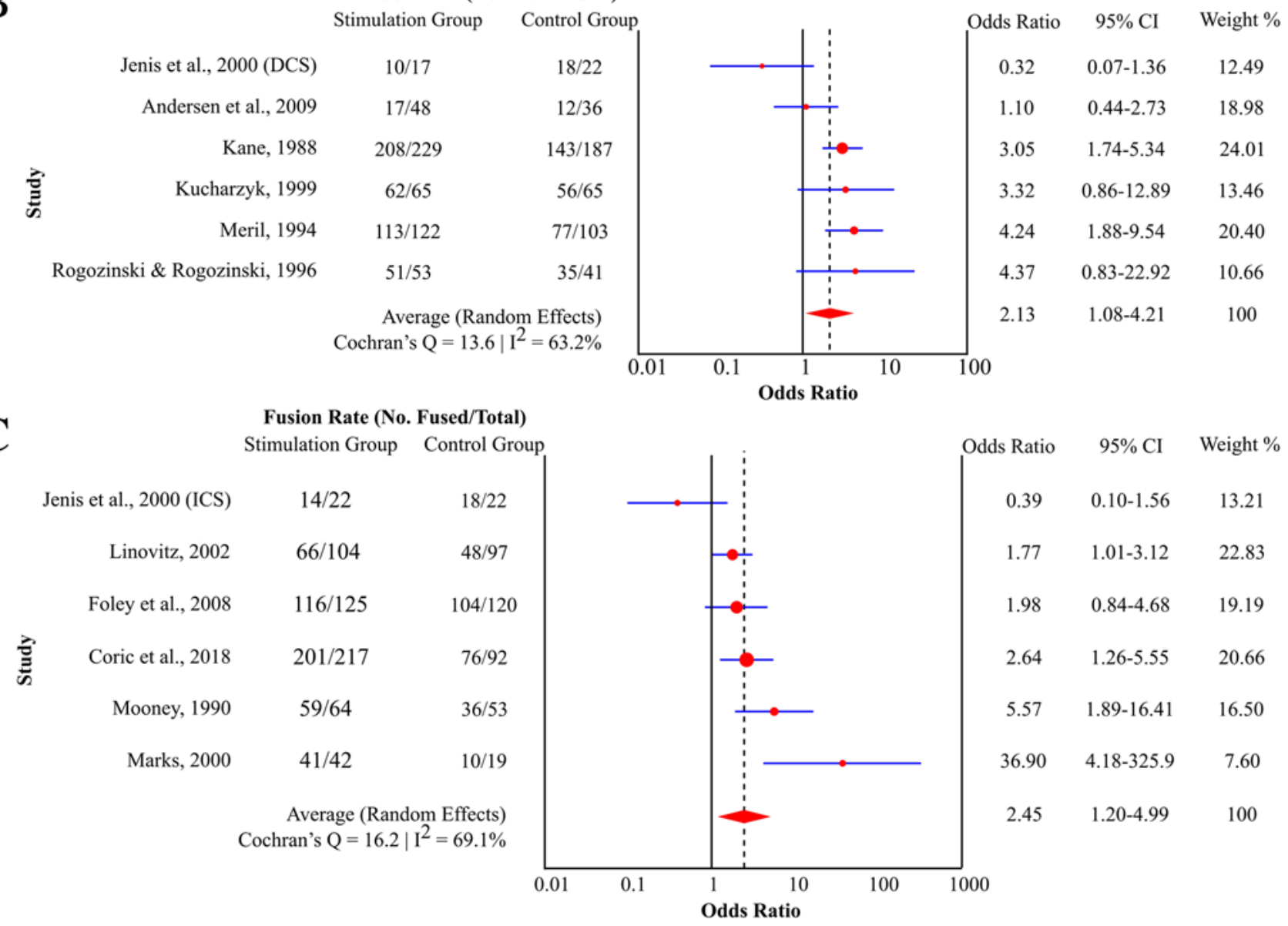

FIG. 3. Forest plots demonstrating random-effects meta-analysis of the fusion rates from all clinical studies (A), only clinical studies examining the effect of DCS on spinal fusion (B), and only clinical studies examining the effect of ICS on spinal fusion (C). Only studies reporting fusion rates for intervention (i.e., electrical stimulation) and control groups are included. Figure is available in color online only.

\section{Effect of CCS on Spinal Fusion}

No preclinical studies were found that described the use of CCS in a spinal fusion model, and only 1 clinical study met our inclusion criteria (Table 3). In that double-blind randomized controlled trial, Goodwin et al. examined the use of CCS in 179 adults undergoing oneor two-level fusions in which one of the following techniques was used: anterior lumbar interbody fusion, pos- 
terior lumbar interbody fusion, or posterolateral lumbar fusion. ${ }^{47}$ All patients were instructed to use the stimulation device (precursor of the Biomet OrthoPak [Zimmer Biomet]) for 24 hours/day for 9 months or until fusion was confirmed radiologically. At the 12-month followup visit, no significant difference in fusion rates was detected between CCS-treated (90.6\%) and control (81.9\%) patients (Table 4).

\section{Effect of ICS on Spinal Fusion}

Thirteen total studies-6 preclinical and 7 clinicaldescribing the results of ICS met our inclusion criteria. Of these, 3 preclinical and 6 clinical studies were included in the meta-analysis.

\section{Preclinical Data}

Preclinical studies described the effects of ICS in dog $(n=3)$, rabbit $(n=2)$, and rat $(n=1)$ models using posterior facet fusion $(n=2)$ or posterolateral inter-transverse process fusion $(n=4)$ of the lumbar spine. Four studies involved one-level procedures, whereas 2 involved multilevel fusions ( $\geq 2$ levels). All studies used either autograft $(\mathrm{n}=5)$ or synthetic bone graft $(\mathrm{n}=1) ; 2$ studies used instrumentation (Table 2).

The fusion rate varied widely across studies, ranging from $0 \%$ to $81 \%$ in treated groups and from $0 \%$ to $60 \%$ in controls (Supplemental Fig. 2B). In the aggregate, the included studies failed to show a significant difference in fusion rates between ICS-treated animals and controls (OR 3.08 [95\% CI 0.88-10.72], p > 0.05) (Table 4).

\section{Clinical Data}

All clinical studies investigating the effect of ICS on spinal fusion examined adult patients (Table 3). Three of the studies examined the effects in only patients with difficult-to-fuse spines, defined by the studies as 1) patients with a herniated nucleus pulposus, degenerative disc disease, spondylolisthesis, spinal stenosis, and/or those who had undergone a prior failed fusion; ${ }^{14}$ 2) those who smoked and/or were undergoing multilevel fusion with an allograft; ${ }^{34}$ or 3 ) those who were age $\geq 65$ years, actively smoked, were undergoing multilevel fusion, had undergone a prior failed fusion, had diabetes, and/or had osteoporosis. ${ }^{26}$ Two studies restricted patients to those without a history of spine surgery, while the remaining 5 included both index and revision procedures. Three studies involved only posterior/posterolateral fusion procedures, 3 involved only interbody procedures, and 1 involved either type of procedure. The spinal segments investigated were cervical $(n=2)$ and lumbar/lumbosacral $(n=5)$. Autograft alone was used in 1 study, allograft alone in 1 study, and autograft and/or allograft in 5 studies. Instrumentation was used in all patients in 4 studies, some patients in 2 studies, and none of the patients in 1 study.

Fusion rates varied between $63 \%$ and $98 \%$ in the ICS group and between $49 \%$ and $87 \%$ in the control group (Supplemental Fig. 3C). Patients receiving ICS were found to have significant improvements in overall fusion rate relative to control patients (OR 2.45 [95\% CI 1.20-4.99], $\mathrm{p}=$ 0.014) (Table 4 and Fig. 3C).

\section{Subanalysis of Clinical Data}

On meta-analysis, patients receiving some form of electrical stimulation were found to have a $126 \%$ increase in the odds of a successful fusion by last follow-up compared to controls (Fig. 3A). Table 5 summarizes the subgroup meta-analyses of the clinical data. The variables investigated include those listed as characteristic of patients with difficult-to-fuse spines, patients with a history of smoking, those undergoing revision surgery, those in whom interbody fusion is performed, and those undergoing a multilevel fusion, as well as the surgical level that was treated, the type of graft material used, and whether instrumentation was placed.

Notably, one or more electrical stimulation therapies resulted in statistically significant increases in the fusion rates compared to no stimulation in the following subgroups: patients with difficult-to-fuse spines, smokers, nonsmokers, patients undergoing index procedures, and those undergoing interbody fusions, single-level fusions, multilevel fusions, cervical fusions, lumbar/lumbosacral fusions, fusions with allograft alone, fusions with instrumentation, and fusions without instrumentation. In contrast, significant differences could not be detected between the fusion rates of patients receiving electrical stimulation therapy and controls in the following subgroups: revision surgery, posterior/posterolateral fusion subgroups, and autograft alone (Table 5).

\section{Discussion}

Spinal fusion is performed in the treatment of spinal pathologies of hundreds of thousands of Americans annually. Although most patients experience good outcomes, many experience nonunion, which can be associated with pain, persistent neurological compromise, and need for revision surgery. ${ }^{24}$ One class of surgical adjuvant therapies designed to avoid this outcome is electrical stimulation, including DCS, CCS, and ICS. In the current article, we have reported on the results of a systematic review and metaanalysis that evaluated the existing preclinical and clinical literature with the goal of addressing two questions: 1) To what degree does the technology improve bony fusion in animal models? 2) To what degree does the technology facilitate bony fusion in humans? We found that both DCS and ICS lead to significant improvements in fusion rates in humans and that DCS also produces significant increases in fusion rates in preclinical studies. Considering all electrical stimulation modalities as a whole, we found that electrical stimulation can significantly increase fusion rates among patients undergoing open fusion operations for a range of spinal pathologies. Subanalyses suggested that this effect persists in patients with difficult-to-fuse spines, smokers, those undergoing index procedures, and those undergoing interbody fusion. Further analyses investigating the effects based on the number of levels fused and whether instrumentation was used suggested that these variables do not alter the fusion benefits of electrical stimulation devices (Table 4).

The merits of any technology can be winnowed down to two questions: 1) Does it work? 2) Is it an economical means of achieving the goal? For medical technologies, 
Cottrill et al.

TABLE 5. Random-effects subgroup meta-analysis of the clinical data*

\begin{tabular}{|c|c|c|c|c|c|c|}
\hline \multirow[b]{2}{*}{ Variable } & \multirow{2}{*}{$\begin{array}{c}\text { Type of } \\
\text { EST }\end{array}$} & \multirow[b]{2}{*}{ Authors \& Year } & \multicolumn{2}{|c|}{ Fusion Rate (no. fused/total) } & \multirow{2}{*}{$\begin{array}{c}\text { Cochran's } \\
Q\end{array}$} & \multirow{2}{*}{$\begin{array}{c}\text { OR }(95 \% \mathrm{Cl}) \& \\
\text { p Value }\end{array}$} \\
\hline & & & Stimulation Group & Control Group & & \\
\hline \multirow{8}{*}{$\begin{array}{l}\text { Studies limited to } \\
\text { difficult-to-fuse } \\
\text { spines } †\end{array}$} & \multirow{4}{*}{ DCS } & Andersen et al., 2009 & $17 / 48$ & $12 / 36$ & \multirow{4}{*}{3.21} & \multirow{4}{*}{$\begin{array}{l}2.14(0.94-4.86) \\
\quad p>0.05\end{array}$} \\
\hline & & Kucharzyk, 1999 & $62 / 65$ & $56 / 65$ & & \\
\hline & & Kane, 1988 & $25 / 31$ & $15 / 28$ & & \\
\hline & & Overall $(95 \% \mathrm{Cl})$ & $73.3 \%(31.3-98.8 \%)$ & $59.2 \%(24.9-89.0 \%)$ & & \\
\hline & \multirow{3}{*}{ ICS } & Foley et al., 2008 & $116 / 125$ & $104 / 120$ & \multirow{3}{*}{0.25} & \multirow{3}{*}{$\begin{array}{l}2.34(1.33-4.10) ; p= \\
\quad 0.003\end{array}$} \\
\hline & & Coric et al., 2018 & $201 / 217$ & $76 / 92$ & & \\
\hline & & Overall $(95 \% \mathrm{Cl})$ & $92.4 \%(89.4-95.0 \%)$ & $84.6 \%(79.5-89.1 \%)$ & & \\
\hline & All & Overall $(95 \% \mathrm{Cl})$ & $82.5 \%(64.1-95.2 \%)$ & $70.8 \%(52.2-86.3 \%)$ & 3.59 & $\begin{array}{c}2.18(1.43-3.32) \\
p<0.001\end{array}$ \\
\hline \multirow{9}{*}{ Smoker } & \multirow{4}{*}{ DCS } & Meril, 1994 & $85 / 92$ & $42 / 59$ & \multirow{4}{*}{4.44} & \multirow{4}{*}{$\begin{array}{l}2.46(0.71-8.55) \\
\quad p>0.05\end{array}$} \\
\hline & & Rogozinski \& Rogozinski, 1996 & $24 / 26$ & $14 / 18$ & & \\
\hline & & Jenis et al., 2000 & $5 / 10$ & $8 / 13$ & & \\
\hline & & Overall $(95 \% \mathrm{Cl})$ & $83.1 \%(62.5-96.6 \%)$ & $70.5 \%(60.9-79.3 \%)$ & & \\
\hline & \multirow{4}{*}{ ICS } & Mooney, 1990 & $24 / 27$ & $12 / 20$ & \multirow{4}{*}{8.05} & \multirow{4}{*}{$\begin{array}{l}4.48(0.45-44.26) \\
\quad p>0.05\end{array}$} \\
\hline & & Marks, 2000 & $18 / 19$ & $0 / 3$ & & \\
\hline & & Jenis et al., 2000 & $6 / 12$ & $8 / 13$ & & \\
\hline & & Overall $(95 \% \mathrm{Cl})$ & $80.3 \%(55.2-96.6 \%)$ & $47.0 \%(20.2-74.7 \%)$ & & \\
\hline & All & Overall $(95 \% \mathrm{Cl})$ & $82.2 \%(68.6-92.5 \%)$ & $62.5 \%(49.3-74.8 \%)$ & 12.50 & $\begin{array}{l}2.84(1.00-8.11) \\
p=0.05\end{array}$ \\
\hline \multirow{9}{*}{ Nonsmoker } & \multirow{4}{*}{ DCS } & Meril, 1994 & $26 / 28$ & $14 / 20$ & \multirow{4}{*}{1.45} & \multirow{4}{*}{$\begin{array}{l}3.79(0.99-14.53) \\
\quad p=0.05\end{array}$} \\
\hline & & Rogozinski \& Rogozinski, 1996 & $27 / 27$ & $21 / 23$ & & \\
\hline & & Jenis et al., 2000 & $6 / 7$ & $8 / 9$ & & \\
\hline & & Overall $(95 \% \mathrm{Cl})$ & $94.1 \%(82.8-99.6 \%)$ & $81.9 \%(67.1-93.0 \%)$ & & \\
\hline & & Mooney, 1990 & $35 / 37$ & $24 / 33$ & & \\
\hline & ICS & Marks, 2000 & $23 / 23$ & $10 / 16$ & 6.37 & 3.66 (0.34-39.8); \\
\hline & טעו & Jenis et al., 2000 & $7 / 10$ & $8 / 9$ & 0.31 & $p>0.05$ \\
\hline & & Overall $(95 \% \mathrm{Cl})$ & $91.5 \%(74.4-99.6 \%)$ & $71.7 \%(59.9-82.2 \%)$ & & \\
\hline & All & Overall $(95 \% \mathrm{Cl})$ & $93.1 \%(85.0-98.2 \%)$ & $77.0 \%(67.3-85.4 \%)$ & 7.81 & $\begin{array}{c}3.58(1.09-11.8) \\
p=0.04\end{array}$ \\
\hline & & Meril, 1994 & $101 / 109$ & $69 / 92$ & & \\
\hline & DCS & Rogozinski \& Rogozinski, 1996 & $32 / 34$ & $24 / 27$ & 0.50 & $\begin{array}{l}3.69(1.69-8.01) ; p= \\
0.001\end{array}$ \\
\hline & & Overall $(95 \% \mathrm{Cl})$ & $92.4 \%(87.6-96.2 \%)$ & $80.1 \%(66.1-91.1 \%)$ & & \\
\hline & ccs & Goodwin et al., 1999 & $77 / 85$ & $77 / 94$ & 0 & $2.12(0.87-5.21)$ \\
\hline Index surgery (no & ou & Overall $(95 \% \mathrm{Cl})$ & $90.6 \%(82.3-95.8 \%)$ & $81.9 \%(72.6-89.1 \%)$ & 0 & $p>0.05$ \\
\hline prior back sur- & & Mooney, 1990 & $59 / 64$ & $36 / 53$ & & \\
\hline gery) & ICS & Marks, 2000 & $38 / 38$ & $6 / 14$ & 078 & 5.52 (1.17-25.95); \\
\hline & IUS & Linovitz et al., 2002 & $66 / 104$ & $48 / 97$ & 9.10 & $p=0.03$ \\
\hline & & Overall $(95 \% \mathrm{Cl})$ & $88.5 \%(60.6-100 \%)$ & $55.0 \%(40.7-69.0 \%)$ & & \\
\hline & All & Overall $(95 \% \mathrm{Cl})$ & $90.0 \%(78.9-97.3 \%)$ & $69.2 \%(55.6-81.2 \%)$ & 11.14 & $\begin{array}{l}3.24(1.69-6.21) ; p< \\
\quad 0.001\end{array}$ \\
\hline & & Meril, 1994 & $12 / 13$ & $8 / 11$ & & \\
\hline & DCS & Rogozinski \& Rogozinski, 1996 & $19 / 19$ & $11 / 14$ & 0.24 & 6.56 (0.98-44.0); \\
\hline Revision surgery & & Overall $(95 \% \mathrm{Cl})$ & $95.7 \%(83.4-100)$ & $74.2 \%(56.4-88.6 \%)$ & & \\
\hline (prior back & lce & Marks, 2000 & $3 / 4$ & $4 / 5$ & 0 & 0.75 (0.03-17.51); \\
\hline surgery) & ids & Overall $(95 \% \mathrm{Cl})$ & $75 \%(19.4-99.4)$ & $80 \%(28.4-99.5 \%)$ & 0 & $p>0.05$ \\
\hline & All & Overall $(95 \% \mathrm{Cl})$ & $92.0 \%(75.2-99.7 \%)$ & $74.4 \%(58.4-87.6 \%)$ & 1.58 & $\begin{array}{c}3.68(0.72-18.73) \\
p>0.05\end{array}$ \\
\hline
\end{tabular}


» CONTINUED FROM PAGE 120

TABLE 5. Random-effects subgroup meta-analysis of the clinical data*

\begin{tabular}{|c|c|c|c|c|c|c|}
\hline \multirow[b]{2}{*}{ Variable } & \multirow{2}{*}{$\begin{array}{c}\text { Type of } \\
\text { EST }\end{array}$} & \multirow[b]{2}{*}{ Authors \& Year } & \multicolumn{2}{|c|}{ Fusion Rate (no. fused/total) } & \multirow{2}{*}{$\begin{array}{c}\text { Cochran's } \\
\text { Q }\end{array}$} & \multirow{2}{*}{$\begin{array}{c}\text { OR }(95 \% \mathrm{Cl}) \& \\
\text { p Value }\end{array}$} \\
\hline & & & Stimulation Group & Control Group & & \\
\hline \multirow{10}{*}{$\begin{array}{l}\text { Posterior or postero- } \\
\text { lateral fusion }\end{array}$} & \multirow{6}{*}{ DCS } & Kane, 1988 & $208 / 229$ & $143 / 187$ & \multirow{6}{*}{11.34} & \multirow{6}{*}{$\begin{array}{c}1.77(0.78-4.01) \\
p>0.05\end{array}$} \\
\hline & & Kucharzyk, 1999 & $62 / 65$ & $56 / 65$ & & \\
\hline & & Andersen et al., 2009 & $17 / 48$ & $12 / 36$ & & \\
\hline & & Jenis et al., 2000 & $10 / 17$ & $18 / 22$ & & \\
\hline & & Rogozinski \& Rogozinski, 1996 & $51 / 53$ & $35 / 41$ & & \\
\hline & & Overall $(95 \% \mathrm{Cl})$ & $79.4 \%$ (56.7-95.1\%) & $73.6 \%(57.4-87.1 \%)$ & & \\
\hline & \multirow{3}{*}{ ICS } & Jenis et al., 2000 & $14 / 22$ & $18 / 22$ & \multirow{3}{*}{3.94} & \multirow{3}{*}{$\begin{array}{c}0.95(0.22-4.11) \\
p>0.05\end{array}$} \\
\hline & & Linovitz et al., 2002 & $66 / 104$ & $48 / 97$ & & \\
\hline & & Overall $(95 \% \mathrm{Cl})$ & $63.3 \%(54.8-71.4 \%)$ & $64.7 \%(32.7-90.6 \%)$ & & \\
\hline & All & Overall $(95 \% \mathrm{Cl})$ & $77.1 \%(56.3-92.6 \%)$ & $74.7 \%(60.8-86.4 \%)$ & 16.57 & $\begin{array}{l}1.51(0.82-2.79) \\
\quad p>0.05\end{array}$ \\
\hline \multirow{8}{*}{ Interbody fusion } & \multirow{2}{*}{ DCS } & Meril, 1994 & $113 / 122$ & $77 / 103$ & \multirow{2}{*}{0} & \multirow{2}{*}{$\begin{array}{l}4.24(1.88-9.54) ; p< \\
\quad 0.001\end{array}$} \\
\hline & & Overall $(95 \% \mathrm{Cl})$ & $92.6(86.5-96.6 \%)$ & $74.8 \%(65.2-82.8 \%)$ & & \\
\hline & \multirow{5}{*}{ ICS } & Foley et al., 2008 & $116 / 125$ & $104 / 120$ & \multirow{5}{*}{5.68} & \multirow{5}{*}{$\begin{array}{l}3.54(1.71-7.31) ; p= \\
\quad 0.001\end{array}$} \\
\hline & & Coric et al., 2018 & $201 / 217$ & $76 / 92$ & & \\
\hline & & Mooney, 1990 & $59 / 64$ & $36 / 53$ & & \\
\hline & & Marks, 2000 & $19 / 20$ & $6 / 14$ & & \\
\hline & & Overall $(95 \% \mathrm{Cl})$ & $92.3 \%(89.6-94.7 \%)$ & $74.1 \%(59.9-86.2 \%)$ & & \\
\hline & All & Overall $(95 \% \mathrm{Cl})$ & $92.3 \%(90.0-94.4 \%)$ & $74.8 \%(64.4-84.0 \%)$ & 6.08 & $\begin{array}{l}3.56(2.08-6.11) ; p< \\
\quad 0.001\end{array}$ \\
\hline \multirow{8}{*}{ Single-level fusion } & \multirow{4}{*}{ DCS } & Kane, 1988 & $14 / 16$ & $10 / 16$ & \multirow{4}{*}{0.05} & \\
\hline & & Meril, 1994 & $85 / 93$ & $49 / 73$ & & $4.96(2.32-10.63)$ \\
\hline & & Rogozinski \& Rogozinski, 1996 & $16 / 16$ & $18 / 20$ & & $p<0.001$ \\
\hline & & Overall $(95 \% \mathrm{Cl})$ & $92.0 \%(84.6-97.2 \%)$ & $72.7 \%(56.3-86.4 \%)$ & & \\
\hline & & Mooney, 1990 & $43 / 46$ & $29 / 40$ & & \\
\hline & ICS & Marks, 2000 & $18 / 18$ & $6 / 12$ & 1.32 & $\begin{array}{l}8.77(1.70-45.28) ; \\
p=0.01\end{array}$ \\
\hline & & Overall $(95 \% \mathrm{Cl})$ & $95.2 \%(87.0-99.5 \%)$ & $64.1 \%(42.7-82.8 \%)$ & & \\
\hline & All & Overall $(95 \% \mathrm{Cl})$ & $93.1 \%(88.5-96.6 \%)$ & $69.6 \%(58.8-79.4 \%)$ & 1.68 & $\begin{array}{c}5.56(2.91-10.64) \\
p<0.001\end{array}$ \\
\hline & & Kane, 1988 & $11 / 15$ & $5 / 12$ & & \\
\hline & DCS & Meril, 1994 & $23 / 24$ & $26 / 28$ & 034 & $3.40(1.15-10.0)$ \\
\hline & UUS & Rogozinski \& Rogozinski, 1996 & $35 / 37$ & $17 / 21$ & 0.34 & $p=0.03$ \\
\hline & & Overall $(95 \% \mathrm{Cl})$ & $89.2 \%(76.1-97.5 \%)$ & $74.6 \%(45.5-95.0 \%)$ & & \\
\hline Multilevel ( $\geq 2$ ) fusion & & Mooney, 1990 & $16 / 18$ & $7 / 13$ & & \\
\hline & ICS & Marks, 2000 & $23 / 24$ & $4 / 7$ & 0.34 & $\begin{array}{l}9.46(2.16-41.43) \\
p=0.003\end{array}$ \\
\hline & & Overall $(95 \% \mathrm{Cl})$ & $91.4 \%(81.4-97.8 \%)$ & $54.6 \%(34.0-74.4 \%)$ & & \\
\hline & All & Overall $(95 \% \mathrm{Cl})$ & $90.4 \%(83.4-95.6 \%)$ & $68.0 \%(46.3-86.2 \%)$ & 1.88 & $\begin{array}{c}4.86(2.03-11.62) \\
p<0.001\end{array}$ \\
\hline & & Foley et al., 2008 & $116 / 125$ & $104 / 120$ & & \\
\hline Cervical fusion & ICS & Coric et al., 2018 & $201 / 217$ & $76 / 92$ & 0.25 & $\begin{array}{l}2.34(1.33-4.10) ; p= \\
0.003\end{array}$ \\
\hline & & Overall $(95 \% \mathrm{Cl})$ & $92.4 \%(89.4-95.0 \%)$ & $84.6 \%(79.5-89.1 \%)$ & & \\
\hline & & Kane, 1988 & $208 / 229$ & $143 / 187$ & & \\
\hline & & Meril, 1994 & $113 / 122$ & $77 / 103$ & & \\
\hline & & Rogozinski \& Rogozinski, 1996 & $51 / 53$ & $35 / 41$ & & \\
\hline $\begin{array}{l}\text { Lumbar or lumbosa- } \\
\text { cral fusion }\end{array}$ & DCS & Kucharzyk, 1999 & $62 / 65$ & $56 / 65$ & 13.60 & $\begin{array}{l}2.13(1.08-4.21) ; p= \\
0.030\end{array}$ \\
\hline & & Jenis et al., 2000 & $10 / 17$ & $18 / 22$ & & \\
\hline & & Andersen et al., 2009 & $17 / 48$ & $12 / 36$ & & \\
\hline & & Overall $(95 \% \mathrm{Cl})$ & $82.2 \%(65.8-94.1 \%)$ & $73.9 \%(61.7-84.4 \%)$ & & \\
\hline
\end{tabular}


Cottrill et al.

» CONTINUED FROM PAGE 121

TABLE 5. Random-effects subgroup meta-analysis of the clinical data*

\begin{tabular}{|c|c|c|c|c|c|c|}
\hline \multirow{2}{*}{ Variable } & \multirow{2}{*}{$\begin{array}{c}\text { Type of } \\
\text { EST }\end{array}$} & \multirow[b]{2}{*}{ Authors \& Year } & \multicolumn{2}{|c|}{ Fusion Rate (no. fused/total) } & \multirow{2}{*}{$\begin{array}{c}\text { Cochran's } \\
Q\end{array}$} & \multirow{2}{*}{$\begin{array}{c}\text { OR }(95 \% \mathrm{Cl}) \& \\
\text { p Value }\end{array}$} \\
\hline & & & Stimulation Group & Control Group & & \\
\hline \multirow{8}{*}{$\begin{array}{l}\text { Lumbar or lumbo- } \\
\text { sacral fusion } \\
\text { (cont'd) }\end{array}$} & \multirow{2}{*}{ CCS } & Goodwin et al., 1999 & $77 / 85$ & $77 / 94$ & \multirow{2}{*}{0} & \multirow{2}{*}{$\begin{array}{c}2.12(0.87-5.21) \\
p>0.05\end{array}$} \\
\hline & & Overall $(95 \% \mathrm{Cl})$ & $90.6 \%(82.3-95.8 \%)$ & $81.9 \%(72.6-89.1 \%)$ & & \\
\hline & \multirow{5}{*}{ ICS } & Mooney, 1990 & $59 / 64$ & $36 / 53$ & \multirow{5}{*}{15.90} & \multirow{5}{*}{$\begin{array}{l}2.84(0.76-10.72) \\
\quad p>0.05\end{array}$} \\
\hline & & Marks, 2000 & $41 / 42$ & $10 / 19$ & & \\
\hline & & Jenis et al., 2000 & $14 / 22$ & $18 / 22$ & & \\
\hline & & Linovitz et al., 2002 & $66 / 104$ & $48 / 97$ & & \\
\hline & & Overall $(95 \% \mathrm{Cl})$ & $81.6 \%(59.9-96.0 \%)$ & $62.2 \%(47.6-75.7 \%)$ & & \\
\hline & All & Overall $(95 \% \mathrm{Cl})$ & $82.9 \%(72.3-91.4 \%)$ & $70.9 \%(61.6-79.4 \%)$ & 29.68 & $\begin{array}{l}2.25(1.34-3.80) ; p= \\
\quad 0.002\end{array}$ \\
\hline \multirow{10}{*}{ Autograft } & \multirow{5}{*}{ DCS } & Kane, 1988 & $208 / 229$ & $143 / 187$ & \multirow{5}{*}{8.86} & \multirow{5}{*}{$\begin{array}{l}2.03(0.73-5.65) \\
\quad p>0.05\end{array}$} \\
\hline & & Meril, 1994 & $51 / 53$ & $35 / 41$ & & \\
\hline & & Kucharzyk, 1999 & $62 / 65$ & $56 / 65$ & & \\
\hline & & Jenis et al., 2000 & $10 / 17$ & $18 / 22$ & & \\
\hline & & Overall $(95 \% \mathrm{Cl})$ & $89.4 \%(79.7-96.2 \%)$ & $80.4 \%(75.1-85.2 \%)$ & & \\
\hline & \multirow{4}{*}{ ICS } & Mooney, 1990 & $23 / 25$ & $14 / 19$ & \multirow{4}{*}{10.07} & \multirow{4}{*}{$\begin{array}{l}2.88(0.28-29.58) \\
\quad p>0.05\end{array}$} \\
\hline & & Marks, 2000 & $19 / 20$ & $5 / 11$ & & \\
\hline & & Jenis et al., 2000 & $14 / 22$ & $18 / 22$ & & \\
\hline & & Overall $(95 \% \mathrm{Cl})$ & $84.0 \%(63.6-97.0 \%)$ & $68.9 \%(49.5-85.3 \%)$ & & \\
\hline & All & Overall $(95 \% \mathrm{Cl})$ & $87.4 \%(78.9-93.9 \%)$ & $78.5 \%(72.0-84.4 \%)$ & 19.39 & $\begin{array}{l}2.14(0.85-5.37) ; \\
\quad p>0.05\end{array}$ \\
\hline \multirow{4}{*}{ Allograft } & \multirow{4}{*}{ ICS } & Mooney, 1990 & $25 / 27$ & $16 / 22$ & \multirow{4}{*}{2.28} & \\
\hline & & Marks, 2000 & $11 / 11$ & $4 / 7$ & & 2.86 (1.18-6.95); \\
\hline & & Foley et al., 2008 & $116 / 125$ & $104 / 120$ & & $p=0.02$ \\
\hline & & Overall $(95 \% \mathrm{Cl})$ & $92.8 \%(88.3-96.2 \%)$ & $76.7 \%(59.2-90.4 \%)$ & & \\
\hline & & Meril, 1994 & $24 / 24$ & $51 / 63$ & & \\
\hline & & Rogozinski \& Rogozinski, 1996 & $51 / 53$ & $35 / 41$ & & \\
\hline & DCS & Kucharzyk, 1999 & $62 / 65$ & $56 / 65$ & 9.15 & $\begin{array}{l}2.25(0.50-10.1) ; \\
n>0.05\end{array}$ \\
\hline & & Jenis et al., 2000 & $10 / 17$ & $18 / 22$ & & \\
\hline & & Overall $(95 \% \mathrm{Cl})$ & $91.4 \%(77.7-98.9 \%)$ & $83.2 \%(77.6-88.1 \%)$ & & \\
\hline & & Mooney, 1990 & $44 / 48$ & $28 / 39$ & & \\
\hline With instrumentation & & Marks, 2000 & $9 / 10$ & $1 / 1$ & & \\
\hline & ICS & Jenis et al., 2000 & $14 / 22$ & $18 / 22$ & 737 & 1.92 (0.94-3.93); \\
\hline & 10s & Foley et al., 2008 & $116 / 125$ & $104 / 120$ & 1.01 & $p>0.05$ \\
\hline & & Coric et al., 2018 & $201 / 217$ & $76 / 92$ & & \\
\hline & & Overall $(95 \% \mathrm{Cl})$ & $88.5 \%(81.4-94.1 \%)$ & $82.4 \%(77.3-86.9 \%)$ & & \\
\hline & All & Overall $(95 \% \mathrm{Cl})$ & $89.8 \%(83.8-94.6 \%)$ & $82.8 \%(79.3-86.1 \%)$ & 16.44 & $\begin{array}{c}1.94(1.01-3.73) \\
p=0.05\end{array}$ \\
\hline & & Kane, 1988 & $208 / 229$ & $143 / 187$ & & \\
\hline & DCs & Meril, 1994 & $89 / 98$ & $26 / 40$ & 0 & 2.64 (1.20-5.81); \\
\hline & DUS & Andersen et al., 2009 & $17 / 48$ & $12 / 36$ & 0.92 & $p=0.02$ \\
\hline & & Overall $(95 \% \mathrm{Cl})$ & $75.9 \%(45.3-96.3 \%)$ & $59.3 \%(34.1-82.2 \%)$ & & \\
\hline Without instrumenta- & & Mooney, 1990 & $15 / 16$ & $8 / 14$ & & \\
\hline tion & ICS & Marks, 2000 & $32 / 32$ & $9 / 18$ & 807 & 7.71 (0.86-69.38); \\
\hline & סט & Linovitz et al., 2002 & $66 / 104$ & $48 / 97$ & 0.01 & $p>0.05$ \\
\hline & & Overall $(95 \% \mathrm{Cl})$ & $88.2 \%(54.7-99.9 \%)$ & $50.4 \%(41.9-58.9 \%)$ & & \\
\hline & All & Overall $(95 \% \mathrm{Cl})$ & $82.2 \%(63.7-95.0 \%)$ & $56.0 \%(40.7-70.7 \%)$ & 14.03 & $\begin{array}{l}3.01(1.56-5.84) ; p= \\
\quad 0.001\end{array}$ \\
\hline
\end{tabular}


EST = electrical stimulation technology.

Boldface type indicates statistical significance.

* Only studies reporting the fusion rates for both the intervention (i.e., electrical stimulation) and control groups were included in the meta-analysis.

† These studies included only patients with known risk factors for pseudarthrosis: 1) age > 60 years; 5 2) failed prior fusion, grade II or worse spondylolisthesis, multilevel fusion, and/or other high-risk medical condition (e.g., gross obesity) (select cohort within study); ${ }^{57} 3$ ) multiple prior spine surgeries, failed prior fusion, segmental instability, spinal stenosis, and/or spondylolisthesis; ${ }^{60} 4$ ) age $\geq 65$ years, active smoker, multilevel fusion, prior failed fusion, diabetic, and/or osteoporotic; ${ }^{26}$ or 5 ) active smokers and/or multilevel fusion. ${ }^{34}$

we also consider the safety of the technology. Our review mainly addresses the first of these questions-namely, whether electrical stimulation is an effective means of promoting bony fusion. On the whole, our results suggest that the answer to this question is yes, as the results of our pooled analysis demonstrated significantly higher odds of fusion in patients treated with electrical stimulation (OR 2.26, $\mathrm{p}<0.001)$. However, more in-depth investigation suggests that the majority of these results are driven by DCS and ICS. Between these 2 technologies, though, there appears to be no difference in efficacy.

This brings us to considering the questions of economics and safety profiles: 1) Are ICS and DCS economical means of promoting bony fusion? 2) Are they safe? The latter is most easily answered as both implantable DCS and noninvasive ICS devices have been approved under the relatively stringent FDA premarket approval process (class III devices) based on results of randomized controlled trials. $5,34,47,53,57,72$ The former question, i.e., whether the DCS and ICS devices are economical, is one that is harder to answer.

At present there are no high-quality studies evaluating the cost-effectiveness of electrical stimulation devices in the spine literature. However, back-of-the-envelope calculations are possible using estimates of device cost, pseudarthrosis rates, and cost of revision surgery. Prior studies of pseudarthrosis have found that the direct surgical costs of a revision operation are approximately $\$ 21,113 \pm$ $\$ 11,895$ for cervical operations ${ }^{58}$ and $\$ 28,069 \pm \$ 2508$ for lumbar operations. ${ }^{2}$ To a gross approximation, this reduces to $\$ 25,000$ per reoperation. Based on the present results, the approximate pseudarthrosis rate among patients receiving electrical stimulation therapy is $15 \%$, compared to $27 \%$ in the control population. Of these patients, approximately half may require surgical revision for pseudoarthrosis. . $^{245,61,62,80}$ Accounting for this, the cost of surgical revisions for pseudarthrosis averaged across patients receiving electrical stimulation therapy is $\$ 1875$, compared to $\$ 3375$ for controls. For patients receiving electrical stimulation therapy, though, the cost of the stimulation device is an estimated additional \$4000-\$5000. Therefore, from a strictly financial standpoint, electrical stimulation devices may be a cost-ineffective means of improving fusion rates, except in patients with a high risk of nonunion.

The overall risk of pseudarthrosis among patients with difficult-to-fuse spines-commonly defined as those in whom prior fusion has failed, smokers, and those undergoing multilevel fusion procedures - has been reported to exceed 40\%. ${ }^{5,13,18,57,62}$ Accordingly, the cost of revision operations averaged across these patients may exceed $\$ 10,000$, suggesting that the use of electrical stimulation devices in this patient population may be cost-effective. Consistent with this, Medicare - the largest single insurer in the UScovers these devices only for patients with a history of multilevel fusion or a history of one or more prior failed fusion operations. This analysis does not consider the effect of nonunion on indirect costs, namely, days of lost work and decreased quality of life; however, it is likely that consideration of indirect costs will only increase the cost-effectiveness of these stimulation devices. Additional, high-quality investigation is warranted to evaluate this point.

\section{Study Limitations}

There are several limitations to this study. First, we were forced to exclude 6 preclinical and 3 clinical studies from the meta-analysis as they lacked control groups for estimation of odds ratios. This produces a potential selection bias that may limit the generalizability of the data. Second, the results of the study are based on a combination of prospective and retrospective studies. Retrospective studies are limited in the quality of the data they provide, which consequently limits the generalizability of the results of the present study. Nonetheless, we evaluated the quality of the clinical studies included in the meta-analysis (using the Critical Appraisal Checklists) and deemed each to have sufficient quality to be included in the present review. Additionally, although we provide estimates of the overall effect of electrical stimulation therapies at large and in subgroups, the heterogeneity of the included studies prevents us from answering the following questions: 1) Which patients will benefit most from electrical stimulation technologies? 2) For how long should treatment be continued? Furthermore, the definition of fusion varied between studies, suggesting that the outcome may have been distinct across studies, which would limit the validity of our metaanalysis. We describe this heterogeneity by presenting the definition and method of assessment of spinal fusion used by each study. All clinical studies employed plain radiograph- or CT scan-based radiological assessment, both of which are considered valid techniques in the clinical literature. Although a CT scan provides higher-resolution imaging and is therefore often considered the gold standard for fusion assessment, relative to standard radiography it is more expensive, exposes the patient to high radiation levels, and often provides no additional information..$^{33}$ Nevertheless, the different assessment modalities impart heterogeneity to the results, which we attempted to address by employing random-effects versus fixed-effects models. Lastly, we pooled the results of several different electrical stimulation technologies. Though our results suggest that 
ICS and DCS have similar effects, they employ distinct technologies and have widely different patient compliance levels given that the latter is an implanted device, whereas the former is a wearable device. It is therefore possible that limitations in patient compliance among the ICS group limited the ability of our analysis to see differences in efficacy between the technologies. Given these limitations, it is apparent that future studies are necessary to directly compare the effectiveness of these different electrical stimulation technology modalities.

\section{Conclusions}

Here we report the results of the first systematic review and meta-analysis analyzing the effectiveness of electrical stimulation devices on spinal fusion in the preclinical and clinical literature. We found that these devices lead to significant increases in fusion rates, with a nearly fivefold increase in the odds in preclinical studies and a more than twofold increase in clinical studies. Subanalysis suggested that among the clinical population, DCS and ICS lead to significant decreases in pseudarthrosis rates, whereas CCS does not. Additional research is needed to analyze the cost-effectiveness of electrical stimulation devices to identify those patients in whom these devices are likely to be not only practically effective but also cost-effective.

\section{References}

1. Aaron RK, Ciombor DM, Keeping H, Wang S, Capuano A, Polk C: Power frequency fields promote cell differentiation coincident with an increase in transforming growth factorbeta(1) expression. Bioelectromagnetics 20:453-458, 1999

2. Adogwa O, Owens R, Karikari I, Agarwal V, Gottfried ON, Bagley CA, et al: Revision lumbar surgery in elderly patients with symptomatic pseudarthrosis, adjacent-segment disease, or same-level recurrent stenosis. Part 2. A cost-effectiveness analysis: clinical article. J Neurosurg Spine 18:147-153, 2013

3. Adogwa O, Parker SL, Shau D, Mendelhall SK, Cheng J, Aaronson O, et al: Long-term outcomes of revision fusion for lumbar pseudarthrosis: clinical article. J Neurosurg Spine 15:393-398, 2011

4. Aleem IS, Aleem I, Evaniew N, Busse JW, Yaszemski M, Agarwal A, et al: Efficacy of electrical stimulators for bone healing: a meta-analysis of randomized sham-controlled trials. Sci Rep 6:31724, 2016

5. Andersen T, Christensen FB, Egund N, Ernst C, Fruensgaard $\mathrm{S}, \varnothing$ stergaard $\mathrm{J}$, et al: The effect of electrical stimulation on lumbar spinal fusion in older patients: a randomized, controlled, multi-center trial: part 2: fusion rates. Spine (Phila Pa 1976) 34:2248-2253, 2009

6. Balint R, Cassidy NJ, Cartmell SH: Electrical stimulation: a novel tool for tissue engineering. Tissue Eng Part B Rev 19:48-57, 2013

7. Baranowski TJ, Black J: The mechanism of faradic stimulation of osteogenesis, in Blank M, Findl E (eds): Mechanistic Approaches to Interactions of Electric and Electromagnetic Fields with Living Systems. Boston: Springer, 1987, pp 399-416

8. Blackwell KA, Raisz LG, Pilbeam CC: Prostaglandins in bone: bad cop, good cop? Trends Endocrinol Metab 21:294-301, 2010

9. Blumenthal SL, Baker J, Dossett A, Selby DK: The role of anterior lumbar fusion for internal disc disruption. Spine (Phila Pa 1976) 13:566-569, 1988
10. Bodamyali T, Bhatt B, Hughes FJ, Winrow VR, Kanczler JM, Simon B, et al: Pulsed electromagnetic fields simultaneously induce osteogenesis and upregulate transcription of bone morphogenetic proteins 2 and 4 in rat osteoblasts in vitro. Biochem Biophys Res Commun 250:458-461, 1998

11. Bodamyali T, Kanczler JM, Simon B, Blake DR, Stevens CR: Effect of faradic products on direct current-stimulated calvarial organ culture calcium levels. Biochem Biophys Res Commun 264:657-661, 1999

12. Boden SD, Sumner DR: Biologic factors affecting spinal fusion and bone regeneration. Spine (Phila Pa 1976) 20 (24 Suppl):102S-112S, 1995

13. Bolesta MJ, Rechtine GR II, Chrin AM: Three- and four-level anterior cervical discectomy and fusion with plate fixation: a prospective study. Spine (Phila Pa 1976) 25:2040-2046, 2000

14. Bose B: Outcomes after posterolateral lumbar fusion with instrumentation in patients treated with adjunctive pulsed electromagnetic field stimulation. Adv Ther 18:12-20, 2001

15. Bozic KJ, Glazer PA, Zurakowski D, Simon BJ, Lipson SJ, Hayes WC: In vivo evaluation of coralline hydroxyapatite and direct current electrical stimulation in lumbar spinal fusion. Spine (Phila Pa 1976) 24:2127-2133, 1999

16. Brighton CT, Adler S, Black J, Itada N, Friedenberg ZB: Cathodic oxygen consumption and electrically induced osteogenesis. Clin Orthop Relat Res (107):277-282, 1975

17. Brighton CT, Wang W, Seldes R, Zhang G, Pollack SR: Signal transduction in electrically stimulated bone cells. J Bone Joint Surg Am 83:1514-1523, 2001

18. Brown CW, Orme TJ, Richardson HD: The rate of pseudarthrosis (surgical nonunion) in patients who are smokers and patients who are nonsmokers: a comparison study. Spine (Phila Pa 1976) 11:942-943, 1986

19. Cain CD, Adey WR, Luben RA: Evidence that pulsed electromagnetic fields inhibit coupling of adenylate cyclase by parathyroid hormone in bone cells. J Bone Miner Res 2:437-441, 1987

20. Calandruccio RA, Benton BF: Anterior lumbar fusion. Clin Orthop Relat Res 35:63-68, 1964

21. Cho M, Hunt TK, Hussain MZ: Hydrogen peroxide stimulates macrophage vascular endothelial growth factor release. Am J Physiol Heart Circ Physiol 280:H2357-H2363, 2001

22. Cho PG, Ji GY, Ha Y, Lee HY, Shin DA: Effect of the type of electrical stimulation on spinal fusion in a rat posterolateral spinal fusion model. Spine J 19:1106-1120, 2019

23. Choi YH, Choi JH, Oh JW, Lee KY: Calmodulin-dependent kinase II regulates osteoblast differentiation through regulation of Osterix. Biochem Biophys Res Commun 432:248255, 2013

24. Chun DS, Baker KC, Hsu WK: Lumbar pseudarthrosis: a review of current diagnosis and treatment. Neurosurg Focus 39(4):E10, 2015

25. Cook SD, Patron LP, Christakis PM, Bailey KJ, Banta C, Glazer PA: Direct current stimulation of titanium interbody fusion devices in primates. Spine J 4:300-311, 2004

26. Coric D, Bullard DE, Patel VV, Ryaby JT, Atkinson BL, He $\mathrm{D}$, et al: Pulsed electromagnetic field stimulation may improve fusion rates in cervical arthrodesis in high-risk populations. Bone Joint Res 7:124-130, 2018

27. Cottrill E, Ahmed AK, Lessing N, Pennington Z, Ishida W, Perdomo-Pantoja A, et al: Investigational growth factors utilized in animal models of spinal fusion: systematic review. World J Orthop 10:176-191, 2019

28. Dejardin LM, Kahanovitz N, Arnoczky SP, Simon BJ: The effect of varied electrical current densities on lumbar spinal fusions in dogs. Spine J 1:341-347, 2001

29. Epstein N, Epstein JA, Benjamin V, Ransohoff J: Traumatic myelopathy in patients with cervical spinal stenosis without fracture or dislocation: methods of diagnosis, management, and prognosis. Spine (Phila Pa 1976) 5:489-496, 1980 
30. Feyen JHM, Di Bon A, van der Plas A, Löwik CWGM, Nijweide PJ: Effects of exogenous prostanoids on the proliferation of osteoblast-like cells in vitro. Prostaglandins 30:827-840, 1985

31. Fischer CR, Cassilly R, Cantor W, Edusei E, Hammouri Q, Errico T: A systematic review of comparative studies on bone graft alternatives for common spine fusion procedures. Eur Spine J 22:1423-1435, 2013

32. Flynn JC, Hoque MA: Anterior fusion of the lumbar spine. End-result study with long-term follow-up. J Bone Joint Surg Am 61:1143-1150, 1979

33. Fogel GR, Toohey JS, Neidre A, Brantigan JW: Fusion assessment of posterior lumbar interbody fusion using radiolucent cages: $\mathrm{x}$-ray films and helical computed tomography scans compared with surgical exploration of fusion. Spine J 8:570-577, 2008

34. Foley KT, Mroz TE, Arnold PM, Chandler HC Jr, Dixon RA, Girasole GJ, et al: Randomized, prospective, and controlled clinical trial of pulsed electromagnetic field stimulation for cervical fusion. Spine J 8:436-442, 2008

35. France JC, Norman TL, Buchanan MM, Scheel M, Veale M, Ackerman ES, et al: Direct current stimulation for spine fusion in a nicotine exposure model. Spine J 6:7-13, 2006

36. France JC, Norman TL, Santrock RD, McGrath B, Simon BJ: The efficacy of direct current stimulation for lumbar intertransverse process fusions in an animal model. Spine (Phila Pa 1976) 26:1002-1008, 2001

37. Fredericks DC, Smucker J, Petersen EB, Bobst JA, Gan JC, Simon BJ, et al: Effects of direct current electrical stimulation on gene expression of osteopromotive factors in a posterolateral spinal fusion model. Spine (Phila Pa 1976) 32:174-181, 2007

38. Freeman MF, Tukey JW: Transformations related to the angular and the square root. Ann Math Stat 21:607-611, 1950

39. Friedenberg ZB, Andrews ET, Smolenski BI, Pearl BW, Brighton CT: Bone reaction to varying amounts of direct current. Surg Gynecol Obstet 131:894-899, 1970

40. Friedenberg ZB, Brighton CT: Bioelectric potentials in bone. J Bone Joint Surg Am 48:915-923, 1966

41. Friedenberg ZB, Harlow MC, Heppenstall RB, Brighton CT: The cellular origin of bioelectric potentials in bone. Calcif Tissue Res 13:53-62, 1973

42. Friedenberg ZB, Zemsky LM, Pollis RP, Brighton CT: The response of non-traumatized bone to direct current. J Bone Joint Surg Am 56:1023-1030, 1974

43. Fu R, Selph S, McDonagh M, Peterson K, Tiwari A, Chou R, et al: Effectiveness and harms of recombinant human bone morphogenetic protein-2 in spine fusion: a systematic review and meta-analysis. Ann Intern Med 158:890-902, 2013

44. Fukada E, Yasuda I: On the piezoelectric effect of bone. J Phys Soc Jpn 12:1158-1162, 1957

45. Girardo M, Bettini N, Dema E, Cervellati S: Uninstrumented posterolateral spinal arthrodesis: is it the gold standard technique for I degrees and II degrees grade spondylolisthesis in adolescence? Eur Spine J 18 (Suppl 1):126-132, 2009

46. Glazer PA, Heilmann MR, Lotz JC, Bradford DS: Use of electromagnetic fields in a spinal fusion. A rabbit model. Spine (Phila Pa 1976) 22:2351-2356, 1997

47. Goodwin CB, Brighton CT, Guyer RD, Johnson JR, Light KI, Yuan HA: A double-blind study of capacitively coupled electrical stimulation as an adjunct to lumbar spinal fusions. Spine (Phila Pa 1976) 24:1349-1357, 1999

48. Guizzardi S, Di Silvestre M, Govoni P, Scandroglio R: Pulsed electromagnetic field stimulation on posterior spinal fusions: a histological study in rats. J Spinal Disord 7:3640, 1994

49. Haglin JM, Jain S, Eltorai AEM, Daniels AH: Bone growth stimulation: a critical analysis review. JBJS Rev 5:e8, 2017

50. Hartshorne E: On the causes and treatment of pseudarthrosis, and especially of that form of it sometimes called supernumerary joint. Am J Med 1:143, 1841

51. Hofler RC, Swong K, Martin B, Wemhoff M, Jones GA: Risk of pseudoarthrosis after spinal fusion: analysis from the Healthcare Cost and Utilization Project. World Neurosurg 120:e194-e202, 2018

52. Ito M, Fay LA, Ito Y, Yuan MR, Edwards WT, Yuan HA: The effect of pulsed electromagnetic fields on instrumented posterolateral spinal fusion and device-related stress shielding. Spine (Phila Pa 1976) 22:382-388, 1997

53. Jenis LG, An HS, Stein R, Young B: Prospective comparison of the effect of direct current electrical stimulation and pulsed electromagnetic fields on instrumented posterolateral lumbar arthrodesis. J Spinal Disord 13:290-296, 2000

54. Kahanovitz N, Arnoczky SP: The efficacy of direct current electrical stimulation to enhance canine spinal fusions. Clin Orthop Relat Res (251):295-299, 1990

55. Kahanovitz N, Arnoczky SP, Hulse D, Shires PK: The effect of postoperative electromagnetic pulsing on canine posterior spinal fusions. Spine (Phila Pa 1976) 9:273-279, 1984

56. Kahanovitz N, Arnoczky SP, Nemzek J, Shores A: The effect of electromagnetic pulsing on posterior lumbar spinal fusions in dogs. Spine (Phila Pa 1976) 19:705-709, 1994

57. Kane WJ: Direct current electrical bone growth stimulation for spinal fusion. Spine (Phila Pa 1976) 13:363-365, 1988

58. Kim EJ, Chotai S, Wick JB, Stonko DP, Sivaganesan A, Devin CJ: Patient-reported outcomes and costs associated with revision surgery for degenerative cervical spine diseases. Spine (Phila Pa 1976) 43:E423-E429, 2018

59. Kornblum MB, Fischgrund JS, Herkowitz HN, Abraham DA, Berkower DL, Ditkoff JS: Degenerative lumbar spondylolisthesis with spinal stenosis: a prospective long-term study comparing fusion and pseudarthrosis. Spine (Phila Pa 1976) 29:726-734, 2004

60. Kucharzyk DW: A controlled prospective outcome study of implantable electrical stimulation with spinal instrumentation in a high-risk spinal fusion population. Spine (Phila Pa 1976) 24:465-469, 1999

61. Lamberg TS, Remes VM, Helenius IJ, Schlenzka DK, Yrjönen TA, Osterman KE, et al: Long-term clinical, functional and radiological outcome 21 years after posterior or posterolateral fusion in childhood and adolescence isthmic spondylolisthesis. Eur Spine J 14:639-644, 2005

62. Leven D, Cho SK: Pseudarthrosis of the cervical spine: risk factors, diagnosis and management. Asian Spine J 10:776786, 2016

63. Linovitz RJ, Pathria M, Bernhardt M, Green D, Law MD, McGuire RA, et al: Combined magnetic fields accelerate and increase spine fusion: a double-blind, randomized, placebo controlled study. Spine (Phila Pa 1976) 27:1383-1389, 2002

64. Loguidice VA, Johnson RG, Guyer RD, Stith WJ, Ohnmeiss $\mathrm{DD}$, Hochschuler SH, et al: Anterior lumbar interbody fusion. Spine (Phila Pa 1976) 13:366-369, 1988

65. Lopez AJ, Scheer JK, Dahdaleh NS, Patel AA, Smith ZA: Lumbar spinous process fixation and fusion: a systematic review and critical analysis of an emerging spinal technology. Clin Spine Surg 30:E1279-E1288, 2017

66. Luben RA, Cain CD, Chen MCY, Rosen DM, Adey WR: Effects of electromagnetic stimuli on bone and bone cells in vitro: inhibition of responses to parathyroid hormone by low-energy low-frequency fields. Proc Natl Acad Sci U S A 79:4180-4184, 1982

67. MacEwan MR, Talcott MR, Moran DW, Leuthardt EC: Novel spinal instrumentation to enhance osteogenesis and fusion: a preliminary study. J Neurosurg Spine 25:318-327, 2016

68. Marks RA: Spine fusion for discogenic low back pain: outcomes in patients treated with or without pulsed electromagnetic field stimulation. Adv Ther 17:57-67, 2000

69. Meril AJ: Direct current stimulation of allograft in anterior 
and posterior lumbar interbody fusions. Spine (Phila Pa 1976) 19:2393-2398, 1994

70. Moher D, Cook DJ, Eastwood S, Olkin I, Rennie D, Stroup DF: Improving the quality of reports of meta-analyses of randomised controlled trials: the QUOROM statement. Quality of Reporting of Meta-analyses. Lancet 354:1896-1900, 1999

71. Moola S, Munn Z, Tufanaru C, Aromataris E, Sears K, Sfetcu R, et al: Chapter 7: Systematic reviews of etiology and risk, in Aromataris E, Munn Z (eds): Joanna Briggs Institute Reviewer's Manual. Adelaide: The Joanna Briggs Institute, 2017 (https://reviewersmanual.joannabriggs.org/) [Accessed June 18, 2019]

72. Mooney V: A randomized double-blind prospective study of the efficacy of pulsed electromagnetic fields for interbody lumbar fusions. Spine (Phila Pa 1976) 15:708-712, 1990

73. Morris MT, Tarpada SP, Cho W: Bone graft materials for posterolateral fusion made simple: a systematic review. Eur Spine J 27:1856-1867, 2018

74. Nerubay J, Katznelson A: Clinical evaluation of an electrical current stimulator in spinal fusions. Int Orthop 7:239-242, 1984

75. Nerubay J, Marganit B, Bubis JJ, Tadmor A, Katznelson A: Stimulation of bone formation by electrical current on spinal fusion. Spine (Phila Pa 1976) 11:167-169, 1986

76. Poorman GW, Jalai CM, Boniello AJ, Worley N, McClelland S III, Passias PG: Bone morphogenetic protein in adult spinal deformity surgery: a meta-analysis. Eur Spine J 26:20942102, 2017

77. Rajaee SS, Bae HW, Kanim LE, Delamarter RB: Spinal fusion in the United States: analysis of trends from 1998 to 2008. Spine (Phila Pa 1976) 37:67-76, 2012

78. Rogozinski A, Rogozinski C: Efficacy of implanted bone growth stimulation in instrumented lumbosacral spinal fusion. Spine (Phila Pa 1976) 21:2479-2483, 1996

79. Salamanna F, Sartori M, Brodano GB, Griffoni C, Martini L, Boriani S, et al: Mesenchymal stem cells for the treatment of spinal arthrodesis: from preclinical research to clinical scenario. Stem Cells Int 2017:3537094, 2017

80. Slizofski WJ, Collier BD, Flatley TJ, Carrera GF, Hellman RS, Isitman AT: Painful pseudarthrosis following lumbar spinal fusion: detection by combined SPECT and planar bone scintigraphy. Skeletal Radiol 16:136-141, 1987

81. Smeeth L, Haines A, Ebrahim S: Numbers needed to treat derived from meta-analyses - sometimes informative, usually misleading. BMJ 318:1548-1551, 1999

82. Stauffer RN, Coventry MB: Anterior interbody lumbar spine fusion. Analysis of Mayo Clinic series. J Bone Joint Surg Am 54:756-768, 1972

83. Stippick TW, Sheller MR: Combined magnetic fields provide robust coverage for interbody and posterolateral lumbar spinal fusion sites. Med Biol Eng Comput 54:113-122, 2016

84. Tejano NA, Puno R, Ignacio JMF: The use of implantable direct current stimulation in multilevel spinal fusion without instrumentation. A prospective clinical and radiographic evaluation with long-term follow-up. Spine (Phila Pa 1976) 21:1904-1908, 1996

85. Tepper OM, Callaghan MJ, Chang EI, Galiano RD, Bhatt $\mathrm{KA}$, Baharestani S, et al: Electromagnetic fields increase in vitro and in vivo angiogenesis through endothelial release of FGF-2. FASEB J 18:1231-1233, 2004

86. Toth JM, Seim HB III, Schwardt JD, Humphrey WB, Wallskog JA, Turner AS: Direct current electrical stimulation increases the fusion rate of spinal fusion cages. Spine (Phila Pa 1976) 25:2580-2587, 2000

87. Tsutsumimoto T, Shimogata M, Yoshimura Y, Misawa H: Union versus nonunion after posterolateral lumbar fusion: a comparison of long-term surgical outcomes in patients with degenerative lumbar spondylolisthesis. Eur Spine J 17:11071112,2008
88. Wang Z, Clark CC, Brighton CT: Up-regulation of bone morphogenetic proteins in cultured murine bone cells with use of specific electric fields. J Bone Joint Surg Am 88:1053-1065, 2006

89. Weiss AJ, Elixhauser A, Andrews RM: Characteristics of operating room procedures in U.S. hospitals, 2011: Statistical Brief \#170, in Healthcare Cost and Utilization Project (HCUP) Statistical Briefs. Rockville, MD: Agency for Healthcare Research and Quality (US), 2014

90. Welch WC, Willis SL, Gerszten PC: Implantable direct current stimulation in para-axial cervical arthrodesis. Adv Ther 21:389-400, 2004

91. Yoshihara H: Rods in spinal surgery: a review of the literature. Spine J 13:1350-1358, 2013

92. Zayzafoon M: Calcium/calmodulin signaling controls osteoblast growth and differentiation. J Cell Biochem 97:56-70, 2006

93. Zhuang H, Wang W, Seldes RM, Tahernia AD, Fan H, Brighton CT: Electrical stimulation induces the level of TGF-betal mRNA in osteoblastic cells by a mechanism involving calcium/calmodulin pathway. Biochem Biophys Res Commun 237:225-229, 1997

94. Zhuo X, Li C, Li B, Li Z, Lv H, Huang J, et al: Effects of combined magnetic fields treatment and nano-hydroxyapatite coating on porous biphasic calcium phosphate bone graft in rabbit spinal fusion model. Spine (Phila Pa 1976) 43:E625E633, 2018

\section{Disclosures}

Dr. Goodwin reports being a consultant for Augmedics and ROM3, having an ownership stake in AOSpine/NREF, and receiving textbook royalties from Kendall Hunt. Dr. Theodore receives royalties from DePuy and Globus Medical Inc.; he is a consultant for Globus. Dr. Witham reports receiving non-study-related grant support from the Gordon and Marilyn Macklin Foundation and Eli Lilly and Company; he is a consultant for DePuy Synthes Spine. Dr. Sciubba is a consultant for Baxter, DePuy Synthes, Globus, K2M, Medtronic, NuVasive, and Stryker. Mr. Cottrill reports receiving non-study-related grant support from the National Institute on Aging (F30AG063445).

\section{Author Contributions}

Conception and design: Sciubba, Cottrill, Pennington. Acquisition of data: Cottrill, Pennington. Analysis and interpretation of data: all authors. Drafting the article: all authors. Critically revising the article: all authors. Reviewed submitted version of manuscript: all authors. Approved the final version of the manuscript on behalf of all authors: Sciubba. Statistical analysis: Cottrill, Pennington, Ahmed. Administrative/technical/material support: Sciubba, Theodore, Witham. Study supervision: Sciubba, Theodore, Witham.

\section{Supplemental Information \\ Online-Only Content}

Supplemental material is available with the online version of the article.

Critical Appraisal Checklists and Supplemental Tables and Figures. https://thejns.org/doi/suppl/10.3171/2019.5.SPINE19465.

\section{Correspondence}

Daniel Sciubba: Johns Hopkins School of Medicine, Baltimore, MD.dsciubb1@jhmi.edu. 